Risky Politics? Associations between Adolescent Risk Preference and Political Engagement Benjamin Oosterhoff ${ }^{1} \&$ Laura Wray-Lake ${ }^{2}$

${ }^{1}$ Department of Psychology, Montana State University, 305 Traphagen Hall, Bozeman, MT 59717

${ }^{2}$ Department of Social Welfare, University of California, 337 Charles E. Young Dr. East Los Angeles, CA 90095

Citation: Oosterhoff, B., \& Wray-Lake, L. (in press). Risky politics? Associations between adolescent risk preference and political engagement. Child Development.

Address correspondence to:

Benjamin Oosterhoff

Department of Psychology

Montana State University

305 Traphagen Hall

Bozeman, MT 59717

USA

E-mail: Benjamin.oosterhoff@ montana.edu

Phone: 517-897-4160 


\begin{abstract}
This study examined associations among adolescent risk preference and political engagement using nationally representative Monitoring the Future data from high school seniors $(N=109,574$; modal age $=18$ years $)$ spanning 1976-2014. Greater risk preference was associated with greater past voting, donating to a campaign, writing government officials, boycotting, and protesting. Greater risk preference was associated with higher future intentions to boycott and protest, but lower intentions to donate to or volunteer for a campaign. In general, associations between risk preference and political engagement became stronger with higher levels of political interest. Results highlight the importance of considering the adaptive role of adolescent risk preference and suggest that political engagement may be a constructive outlet for youth who pursue or are comfortable taking risks.
\end{abstract}

Keywords: political engagement; risk preference; positive youth development 


\section{Risky Politics? Associations between Adolescent Risk Preference and Political Engagement}

Adolescence is a developmental period characterized by greater preference for risk taking and engagement in risky behaviors (Steinberg, 2008). Changes in the dopaminergic system that occur during puberty increase sensation-seeking and reward sensitivity, and as a result, increase the tendency to seek out novel experiences that offer potential for high-intensity emotions (Dahl, 2004; Steinberg, 2008). The greater inclination to engage in risk taking during adolescence has been traditionally viewed as a public health concern (Steinberg, 2008) and has been linked to the increased likelihood of experiencing automobile accidents, violence, substance use, and sexually transmitted diseases during this age period (Steinberg, 2007).

Heightened risk taking during adolescence is also a component of normative, healthy development and serves an adaptive function of promoting autonomy and exploration (Strang, Chein, \& Steinberg, 2013). However, relatively little research has examined the ways in which adolescent risk preference may be connected with positive social behaviors (Do, Guassi, \& Telzer, 2017). One domain of positive development that may be especially fitting for youth with heightened risk preference is political engagement, a constellation of actions related to influencing people and institutions with power on decisions about social issues (Ekman \& Amnå, 2012). For many youth, political engagement represents a novel, adult-oriented behavior that encompasses potential rewards (e.g., feelings of empowerment, reinforced identity, social capital), but also entails potential risks (e.g., failure to influence government, negative appraisals by others, stress in navigating a new system, physical harm, legal trouble). The novelty, challenges, and uncertainties in political participation may mean that youth with greater preference for risk are more prone to become more involved in politics relative to youth who are more risk-averse. Further, activities that seek to explicitly challenge existing political structures 
(e.g., protesting) may entail greater risks for youth than more standard forms of political engagement (e.g., voting), and youth with higher risk preference may be more comfortable participating in these behaviors. Additionally, political engagement in general may be more rewarding for youth with greater personal interest in politics, as involvement may support intrinsic motivation, agency, and autonomy for these youth. The current study used nationally representative samples of high school seniors to examine associations between adolescent risk preference and standard and social movement forms of political engagement and assessed whether these associations vary by levels of political interest.

\section{Developmental Perspectives on Adolescent Risk Taking}

Increases in adolescents' propensity to take risks from childhood through adolescence have normative developmental roots. Neurobiological perspectives propose a dual-process model, whereby reward circuitry involving the ventral striatum matures earlier than the selfregulatory abilities controlled by the prefrontal cortex and encourage greater involvement in novel, adult-like behavior (Romer, 2010). This neurobiological imbalance is thought to lead to greater risk taking during adolescence, which can result in dangerous and unhealthy behaviors, such as delinquency, substance use, and gambling (e.g., Pharo, Sim, Graham, Gross, \& Hayne, 2011). Prior research has shown that risk propensity and related characteristics (e.g., sensation seeking) follow normative development trajectories that parallel age-related change in delinquency and health-risk behaviors (Quinn \& Harden, 2013).

Just as neurobiological changes demonstrate meaningful individual differences across development (Barkley-Levenson, Van Leijenhorst, \& Galván, 2013), researchers have also documented individual differences in explicit risk preference (Rao et al., 2011). Risk preference can be defined as a desire or willingness to engage in varied, novel, and complex sensations and 
experiences (Steinberg, 2004), and individual differences in risk preference have been consistently linked with higher levels of risk-taking behavior during adolescence such as substance use and conduct problems (Keyes et al., 2015). Thus, we know that variability in risk preference during adolescence has meaningful links to problematic risk-taking behavior, yet individual differences in risk preference may also have implications for a broader array of behaviors in adolescence.

Risk taking can manifest in multiple forms (Weber, Blais, \& Betz, 2002), and although a considerable amount of research has been dedicated to studying negative risk taking (e.g., Steinberg, 2008), several positive behaviors necessary for personal growth and positive contributions to society entail potential risks and rewards (e.g., Do et al., 2017). For instance, speaking in front of a group of people, engaging in a contentious political discussion, or joining new political groups entails personal benefits when successful (e.g., social validation or acquisition of social support) but may also entail potential costs when unsuccessful (e.g., social rejection or decreased social status). Adolescent risk-taking may have both negative and positive features, and examining how adolescents' risk preference connects with both positive and negative forms of risk taking is necessary for a more comprehensive understanding of adolescent development.

\section{Risk Preference and Political Engagement}

One way that adolescents may experience risk while expressing positive contributions to society and contributing to personal growth is through political activities (Ekman \& Amnå, 2012; Santos \& Van Daalen, 2018; Šerek, Machackova, \& Macek, 2018; Watts \& Flanagan, 2007). Sociologists have long argued that social and political change results in large part from generational replacement (Mannheim, 1952; Ryder, 1965); that is, as new cohorts of young 
people come of age and begin to participate in politics, they bring fresh perspectives on society's pressing issues and are not as bounded by political conventions or as committed to maintaining the status quo. This is likely why youth have been at the forefront of many major social movements in the U.S. and globally (Costanza-Chock, 2012) and young adults are more likely to engage in social movement activism compared to older adults (Norris, 2004). Yet, political action, particularly social movement behavior, has always occurred among a smaller subset of youth. For example, during the 1960 s civil rights era, a time widely regarded as high in protests and demonstrations, an estimated $15 \%$ of youth were engaged in political activism (Hart \& Gullan, 2010). Similarly, nationally representative U.S. data from 1976 to 2014 revealed that $3.3 \%$ to $10.5 \%$ of 18 year olds had already engaged in some form of political action in their lifetime, yet a substantially larger proportions of youth who had not yet engaged (9.2 to 84.2\%) intended to participate in these activities in the future (Oosterhoff, Kaplow, Layne, \& Pynoos, 2018). Thus, there seems to be a distinct group of young people who are politically engaged during adolescence.

Prior research has identified a number of individual and contextual factors that are associated with adolescents' political behavior, behavioral intentions, beliefs, or knowledge. Key factors include parents' political engagement, parent-adolescent discussion of political events, open classroom climates, opportunities to participate in extracurricular activities, close ties to social networks, higher political interest and efficacy, and sociocognitive competencies such as empathy and future orientation (e.g., Andolina, Jenkins, Zukin, \& Keeter, 2003; McIntosh, Hart, \& Youniss, 2007; Metzger et al., 2018; Wray-Lake \& Sloper, 2016). While helpful in delineating a range of developmental assets that support adolescents' political engagement, research has given relatively less attention to factors that fall outside of traditional conceptualizations of 
'assets'. However, we know that youth involved in political activism have been found to distrust the government (Hart \& Gullan, 2010) and are more likely to have experienced victimization (Oosterhoff et al, 2018) or discrimination (Hope, Keels, \& Durkee, 2016). A broader and more holistic set of correlates of political behavior must be studied to better understand how and why youth become politically engaged.

We posit that participation in political activities pose meaningful risks and rewards for youth and those who have a higher propensity for risk taking are more likely to engage in politics. Youth who voice their political perspectives risk being ostracized or marginalized by adults based on perceived deficiencies in political knowledge, skills, and abilities (Gordon \& Taft, 2011). Further, political engagement often involves experiencing potentially contentious situations such as discussing controversial issues. For many youth, navigating these situations entails social risks of being rejected by peers, family, other adults (McAdam, 1986), or in modern times, the social media community writ large. Some forms of political engagement involve voicing direct opposition to established norms, social and political institutions, or individuals in positions of power, which may result in injury, being arrested, or being criminally charged. Thus, political involvement may have negative legal, social, physical or financial consequences (McAdam, 1986).

Simultaneously, it is also possible that political engagement presents meaningful rewards for youth. Navigating the political system may provide youth with novel, complex, adult-like experiences that provide feelings of empowerment, self-competence, or excitement (Ballard \& Ozer, 2016). Many political activities provide teens with an opportunity to interact with likeminded peers, thus building social capital and possibly contributing to greater feelings of belongingness. Consistent with this perspective, prior research indicates that youth who vote or 
engage in protesting have greater self-reported health and socioeconomic status four years later (Ballard, Hoyt, \& Pachucki, 2018). Moreover, risk preference may enable youth to have the courage to confront social problems and injustices in ways that make a meaningful impact on community or society (Delgado, 2015). Youth who have greater risk preference may be better able to become politically engaged, despite challenges and uncertainties. Thus, although political engagement may entail important risks for adolescents, it also offers opportunities to garner personal benefits and societal contributions. Youth who have a greater preference for risk taking may be more inclined to engage in political action as means of obtaining possible intrapersonal and societal rewards despite the potential risks.

Political and developmental scientists separate standard political participation (i.e., voting, campaigns, and organized political parties or political organizations) from social movement participation (i.e., demonstrations, protests, strikes, riots; Ekman \& Amnå, 2012). A primary distinction between these two dimensions of political action is that standard political behavior involves engaging within the political system to influence elections and the decisions of elected officials, whereas social movement behavior entails working outside of the system to challenge and change the status quo. Research indicates that youth distinguish between standard political and social movement activities in their judgements and justifications for why people should engage in these behaviors (Metzger \& Smetana, 2009; Metzger, Oosterhoff, Ferris, \& Palmer, 2014). Whereas youth view standard political engagement as a social convention meant to ensure the smooth and efficient functioning of democracy, they view social movement behaviors as a combination of social convention and personal choice (Metzger \& Smetana, 2009). Research has also found longitudinal, domain-specific associations between engagement in standard political and social movement behaviors and beliefs about these issues (Metzger, 
Ferris, \& Oosterhoff, 2018). Standard political and social movement behaviors may therefore represent distinct categories of political action with potentially different correlates and motivations.

Both standard political behavior and activism are relatively infrequent among youth as a whole relative to other forms of civic engagement such as community service (Syvertsen, WrayLake, Flanagan, Osgood, \& Briddell, 2011). Because formal political spheres are overwhelmingly dominated by adults and adolescents are rarely welcomed into these arenas (Gordon \& Taft, 2011), risk preference should relate to higher engagement in standard political behavior. Yet, prior research has acknowledged that political activism holds more costs (time, energy) as well as risks compared to other forms of political engagement (McAdam, 1986). Involvement in protests and demonstrations comes with real risks for youth, such as escalated interactions with police or counter-protesters, which could result in serious personal consequences (Santos \& VanDaalen, 2018). Thus, the link between risk preference and political behavior should be much stronger for social movement behaviors.

\section{Variation by Political Interest}

Connections between adolescent risk preference and political engagement may vary based on youths' political interest. Developmental shifts in risk preference are due in part to a greater sensitivity to potential rewards (Steinberg, 2008). Pursuing personal interests is an important component of autonomy (Deci \& Ryan, 2008), and engaging in behaviors that support volition, intrinsic motivation, and personal values are thought to be rewarding to youth (Deci \& Ryan, 2008; Hansen \& Larson, 2007). Thus, involvement in politics may be more rewarding or fulfilling for youth who have greater personal interest in political and social issues. Accordingly, the current study explored whether associations between risk preference and political 
engagement differed for youth with various levels of political interest. Examining the moderating effect of political interest on associations between risk preference and political engagement may help determine the conditions under which risk preference are connected with greater political involvement for youth and provide an important avenue for interventions seeking to enhance political engagement among adolescent risk-takers.

\section{Methodological Considerations}

Testing connections between risk preference and youths' political engagement requires certain methodological considerations. Opportunities to engage in many political behaviors may vary based on election cycles, and there have been notable historical shifts in political engagement over time (Syvertsen et al, 2011). Historical periods and cohorts with heightened national political engagement may attenuate links between risk preference and political participation. Additionally, risk preference and political engagement vary by several demographic characteristics, including adolescent gender, age, parents' education, race/ethnicity, and political ideology (File, 2014; Smith, 2013; Zaff, Hart, Flanagan, Youniss, \& Levine, 2010). Prior research on positive youth development has also demonstrated that involvement in organized activities, community service, and religious organizations are robust predictors of future political engagement (Zaff, Moore, Papillo, \& Williams, 2003). More recently, studies have shown that certain negative community experiences such as victimization may also motivate political participation (Oosterhoff et al., 2018). Further, it is possible that youth are drawn to certain political activities (e.g., protests) as settings to exercise other risk-taking behaviors, such as delinquency or substance use. Thus, it is important to account for these forms of risk taking to isolate the associations between risk preference and political participation. In an effort to address these concerns, this study examined links between risk preference and prior 
political participation, as well as intent to engage in politics among youth who are not currently politically active, while accounting for cohort effects, period effects, and a wide breadth of additional covariates including demographic characteristics, organized and community activity involvement, victimization, delinquency, and substance use.

\section{Current Study}

The primary aim of this study was to examine associations among adolescents' risk preference and various forms of political engagement. Based on prior research and theory, it was hypothesized that greater risk preference would be associated with greater engagement in all forms of political behaviors. However, it was also expected that the strength of this association would be stronger for social movement behaviors (i.e., protesting and boycotting) relative to standard political behaviors (i.e., voting, working on a campaign, donating to a campaign, writing government officials). To provide specificity in our anticipated effects, we analyzed each form of political behavior separately to test these hypotheses. An additional aim was to test whether links between risk preference and political engagement were moderated by political interest. Based on prior research suggesting that the pursuit of personal interests may enhance the rewards of an activity (Hansen \& Larson, 2007), it was hypothesized that associations among risk preference and political engagement would be stronger for youth with higher levels of political interest.

\section{Method}

\section{Participants}

Participants were $12^{\text {th }}$ graders enrolled in consecutive years of the Monitoring the Future (MTF) study (Johnston, Bachman, O’Malley, Schulenberg, \& Miech, 2012). Each year since 1976, nationally representative samples of about 16,00012 th graders have been drawn from 
about 135 public and private schools to examine age-period-cohort changes in substance use and its affiliated risks. This study utilized 39 waves of data available to the public (1976-2014). Each MTF study survey contained a set of core questions common to all forms as well as questions unique to that form. Only Form 2 assessed the constructs of interest; thus, all analyses were limited to youth who received Form 2 (approximately 3,000 participants per wave) and answered questions regarding risk preference, political interest, and political participation.

The final analytic sample consisted of $N=109,574$ high school seniors. Participants were $50.9 \%$ female and $80.2 \%$ were 18 years or older. Participants provided detailed reports of their race and ethnicity at every measurement wave. However, to protect the anonymity of youth from racial and ethnic minority groups represented at low frequencies, the only consistent measure of race/ethnicity available across all waves in the public-use data indicates whether youth identified White or Black. A Hispanic/Latino(a) category was added to the public-use data from 2005 onward and youth reporting a different race or ethnicity were given missing values for race/ethnicity. Based on the race/ethnicity categories provided in the MTF public use data, $67.1 \%$ of youth were White, $12.7 \%$ were Black, $3.1 \%$ were Hispanic, and $17.1 \%$ either did not report their race/ethnicity or this information was censored. Youth varied in the education level of their parents: $14.0 \%$ of mothers (16.3\% of fathers) did not complete high school, $32.0 \%$ of mothers $(27.0 \%$ of fathers) completed high school but did not have any college training, $18.1 \%$ of mothers (15.4\% of fathers) completed some college, $29.3 \%$ of mothers $(31.8 \%$ of fathers) obtained a college degree or higher, and $4.4 \%$ of youth did not report or did not know their mothers' education (7.0\% of youth for fathers). Youth also differed in their political ideology, with $16.5 \%$ identifying as conservative, $27.4 \%$ identifying as moderate, $19.2 \%$ identifying as 
liberal, $29.8 \%$ identifying as 'other' or that they do not know their ideology, and $7.1 \%$ not reporting their ideology.

\section{Measures}

Political Participation. Political participation was measured using six items assessing whether youth had engaged or intended to engage in four standard political activities (i.e., vote, donate to a political campaign, volunteer for a political campaign, write to public officials) and two social movement activities (i.e., boycott, protest). Responses were recorded using a 4-point nominal scale consisting of I probably will not do this, I probably will do this, I have already done this, and I do not know. Dummy codes were created to represent whether youth had already participated (coded 1) or had not participated in the activity (coded 0). Separate dummy codes were also created indicating an intention to participate (coded 1) versus no clear intention to participate for youth who had not already participated in that activity (coded 0). Consistent with prior research (e.g., Oosterhoff et al., 2018; Syversten et al., 2011) and in an effort to be conservative regarding estimates of youths' intended participation, 'I do not know' responses were interpreted as an indicator of uncertainty about intention and recoded into 'no clear intent to participate' among youth who had not yet participated.

Risk Preference. Similar to prior research (Keyes et al., 2015), two items were used to assess adolescents' risk preference: 'I get a real kick out of doing things that are a little dangerous" and "I like to test myself now and then by doing things that are a little risky". Respondents rated each question on a 5-point scale from 1 (disagree) to 5 (agree). Mean scores were calculated $(\alpha=0.71)$, with higher values representing greater risk preference.

Political Interest. Political interest was measured with a single item that stated, "Some people think about what's going on in government very often, and others are not that interested. 
How much of an interest do you take in government and current events?" Responses were provided on a 5-point scale from 1 (no interest at all) to 5 (a very great interest), with higher values indicating greater political interest.

Organized Activity Involvement. Youth reported the extent to which they participated in four categories of school-based activities during the current school year: (1) school newspaper or yearbook, (2) music or other performing arts, (3) athletic teams, (4) and other school clubs or activities. Responses were given on a 5-point scale from 1 (not at all) to 5 (great). Each item was modeled as a separate activity, with higher values indicating greater involvement.

Religious Service Attendance. Religious service attendance was measured with a single item: "How often do you attend religious services?" Responses were given on a 4-point scale from 1 (never) to 4 (about once a week or more), with higher values indicating greater religious service attendance.

Community Service Involvement. Community service involvement was measured with a single item: "How often do you participate in community affairs or volunteer work?" Responses were given on a 5-point scale from 1 (never) to 5 (almost every day), with higher values indicating greater community service involvement.

Victimization. Victimization was measured using seven items assessing the number of times youth experienced various types of physical assault (e.g., assaulted with a weapon) or property damage (e.g., had property valued over $\$ 50$ stolen) during the previous 12 months. The frequency of each type of victimization was recorded on a 5-point scale from 1 (not at all) to 5 (5 + times $)$. Mean scores were calculated $(\alpha=0.74)$, with higher values indicating greater victimization. 
Delinquency. Delinquency was measured using 15 items assessing the frequency at which youth engaged in various law-breaking and anti-social behaviors (e.g., gotten into a serious fight in school or at work) in the past 12 months. Responses ranged from 1 (not at all) to $5(5+$ times $)$. Means were calculated $(\alpha=0.83)$, with high values indicating greater delinquency.

Substance Use. Substance use was measured using two items that assessed the frequency of: (1) using marijuana (weed, pot) or hashish (hash, hash oil) or (2) had more than just a few sips of alcohol in the past 12 months. Marijuana and alcohol use are common during adolescence (Chassin et al., 2004) and have been connected with greater risk preference (Keyes et al., 2015). Responses for each item ranged from 1 ( 0 occasions) to 7 (40 or more occasions). Mean scores were calculated $(\alpha=0.71)$, with high values indicating greater substance use.

Demographic Characteristics. Participants reported their age, gender, race, parents' education, and political ideology. Highest level of mothers' and fathers' education were reported separately on a 6-point scale from 1 (completed grade school or less) to 6 (graduate or professional school after college) and were averaged to create one indicator of parents' education. Political ideology was measured through self-reported identification on a scale from 1 (very conservative) to 5 (very liberal). Election year was coded from the survey forms and characterized by whether data collection occurred the Spring after a national election (coded 1) or not (coded 0). Cohort was also coded from the survey forms. To aid in model convergence, cohort was divided into 9 to 10 year increments such that 1 (1976-1985), 2 (1986-1995), 3 (1996-2005), and 4 (2006-2014).

\section{Analytic Technique}

A series of probit regression models were used to examine associations among adolescent risk preference and political engagement. Consistent with prior research (Oosterhoff et al., 2018), 
the first series of models examined associations among risk preference and adolescents' past standard political behaviors (i.e., voting, writing government, donating to a campaign, volunteering for a campaign), and the second series of models examined associations among risk preference and adolescents' past social movement behavior (i.e., protesting, boycotting). To test whether associations between risk preference and political engagement differed at varying levels of political interest, political interest and risk preference were standardized and used to create an interaction variable included within the overall model. Because political interest was measured on an ordinal scale, significant interactions were probed by plotting the associations among risk preference and political engagement at each response anchor for political interest (no interest at all, a little interest, some interest, a lot of interest, very great interest). For each set of analyses, similar models were estimated to test whether risk preference was also linked with intent to participate in politics among youth who had not yet participated in each specific political activity. Wald tests were used to examine whether the effect of risk preference was stronger for social movement activities relative to standard political activities for each model.

All analyses accounted for demographic characteristics (age, gender, race/ethnicity, parents' education, political ideology, cohort, election year), organized activity involvement (clubs, arts, athletics, other), community service involvement, religious involvement, victimization, delinquency, and substance use and incorporated sampling weights. Given that separate models were estimated for each political behavior, False Discovery Rate (FDR) adjustments were applied to the main effect of risk preference and the risk preference by political interest interaction term to correct for multiple testing (Benjamini \& Hochberg, 1995; estimates available in the Supplemental File). All models specified the dependent variable as categorical and were estimated in Mplus version 7 using WLSMV, which has demonstrated favorable 
properties over other estimation methods when using asymmetric categorical data (Li, 2004). FIML was used to estimate low levels missing data (the majority ranging from $1 \%$ to $6 \%$, although race/ethnicity was missing for $17.1 \%$ ). The magnitude and direction of all effects were similar with and without FIML estimation.

\section{Results}

Table 1 presents descriptive statistics and bivariate correlations for all study variables. As reported elsewhere (Oosterhoff et al., 2018), the most common form of political participation was writing government $(10.5 \%)$, followed by voting $(7.4 \%)$, boycotting $(7.3 \%)$, working on political campaigns $(4.6 \%)$, protesting $(3.6 \%)$, and donating money to a political campaign (3.3\%). Among youth who had not yet participated in political activities, many stated that they would vote in the future $(84.2 \%)$, write to government officials $(20.7 \%)$, boycott $(18.7 \%)$, protest (17.4\%), donate money to a campaign $(16.3 \%)$, or volunteer to work on a political campaign $(9.2 \%)$ in the future. Bivariate correlations indicated that in general, greater parents' education, being from an earlier cohort, endorsing more liberal ideology, greater organized activity and community service involvement, greater experiences of victimization, greater involvement in delinquency and substance use, greater political interest, and greater risk preference were correlated with greater political participation. Similar bivariate correlations were found with intent to engage in future political behavior among those not currently involved (see Supplemental File).

\section{Risk Preference and Standard Political Engagement}

After accounting for covariates, greater risk preference was associated with greater past involvement in a variety of standard political behaviors (see Table 2). Specifically, greater risk preference was associated with a higher likelihood of having voted, donated to a campaign, and 
having written government officials. For each model, these effects were qualified by a risk preference by political interest interaction. Figure 1a-d displays the effect of risk preference on past standard political behavior at varying levels of political interest. The effect of risk preference on past voting and writing government officials was significant if youth endorsed at least a little political interest. The effect of risk preference on past donating to a campaign followed a similar pattern, although the effect was only statistically significant if youth endorsed at least "some" political interest. For all models, the effect of risk taking on past standard political behavior was very small $(\beta \mathrm{s}=.03$ to .06$)$. We did not find evidence of a connection between risk preference and past volunteering for a campaign at any level of political interest.

Next, we examined links between risk preference and intent to engage in future standard political behaviors among youth who had not yet participated (see Table 3). After accounting for covariates, greater risk preference was associated with a lower likelihood of intending to donate to a campaign or volunteer to work on a campaign. Links between risk preference and intent to vote, intent to donate to a campaign, and intent to volunteer for a campaign were qualified by a risk preference by political interest interaction. Figure 1e-g displays the effect of risk preference on intent to engage in specific future standard political behaviors among those who have not participated at varying levels of political interest. The effect of risk preference on intent to donate to a campaign was negative, significant, and of similar magnitude at all levels of political interest. Further, the effect of risk preference on intent to volunteer for a campaign was negative and strong for youth with no political interest and remained negative but weak at all other levels of political interest. Similar to behaviors, associations between risk preference and intent to engage in standard political behaviors were small $(\beta \mathrm{s}=-.02$ to -.14$)$. We did not find evidence of 
a connection between risk preference and intent to vote or write to government officials at any level of political interest.

\section{Risk Preference and Social Movement Engagement}

An additional series of models examined links between risk preference and social movement engagement (see Table 4). After accounting for covariates, greater risk preference was associated with a greater likelihood of past boycotting and protesting. For each model, these effects were qualified by a risk preference by political interest interaction. Figure 2a-b displays the effect of risk preference on past social movement behavior at varying levels of political interest. The effect of risk preference on past boycotting and protesting was significant at all levels of political interest. The effect of risk preference on past protesting appeared to have a linear increase by levels of political interest, and the standardized beta coefficient was nearly twice as large for youth with "a great deal" of political interest relative to those with no political interest. The effect of risk preferences on past boycotting also demonstrated a linear increase with higher levels of political interest, though this increase appeared much smaller relative to past protesting ( $\Delta \beta=.07$ increase for protesting and $\Delta \beta=.02$ increase for boycotting). For all models, risk preferences had a small effect on past social movement behaviors $(\beta \mathrm{s}=.07$ to .14$)$.

Next, we examined links between risk preference and intent to engage in future social movement behaviors among youth who had not yet participated (see Table 5). After accounting for covariates, greater risk preference was associated with greater intentions to boycott and protest among youth not currently engaged. For each model, these effects were qualified by a risk preference by political interest interaction. Figure $2 \mathrm{c}$-d displays the effect of risk preference on intent to engage in future social movement behavior at varying levels of political interest. The effect of risk preference on intent to engage in boycotting was significant at all levels of political 
interest. The effect of risk preference on intent to engage in protesting was higher with at least 'a little' political interest, with the standardized beta coefficient two to three times larger for youth with a little political interest or more relative to those with no political interest. Associations among risk preference and intent to engage in social movement activities were small to moderate $(\beta \mathrm{s}=.22 \text { to } .31)^{1}$.

\section{Comparisons of the Effects for Standard Political and Social Movement Models}

Wald tests were used to examine whether youth risk preference were more strongly associated with social movement activities relative to standard political activities. For models examining associations with past behavior, the main effect of risk preference was stronger for boycotting (Walds $=32.00$ to $110.23, p$ 's $<.001$ ) and protesting (Walds $=46.04$ to $125.35, p$ 's $<$ .001) relative to all forms of standard political activities. A similar pattern was demonstrated for models examining associations with future intent, with the main effect of risk preference being stronger for boycotting (Walds $=1524.39$ to $1984.50, p$ 's $<.001$ ) and protesting (Walds = 2802.95 to $3633.78, p$ 's $<.001$ ) relative to all forms of standard political activities. A full table displaying all results is available in the Supplemental File.

\section{Comparisons of the Effects for Political Behavior and Intent}

Supplemental analyses were performed to determine if risk preference was more strongly associated with greater past political behavior relative to intent. Specifically, we estimated a series of multinomial probit regressions with political behavior coded as past behavior, intent, and neither behavior/intent specified as dependent variables and past behavior indicated as the reference category. These models were similar to the binary probit regressions models estimated

\footnotetext{
${ }^{1}$ Sensitivity analyses were performed to examine our hypothesized effects varied by cohort for all models. Given that the effect of cohort may be non-linear, cohort was also coded from the survey forms and divided into 9 to 10 year increments such that 1 (1976-1985), 2 (1986-1995), 3 (1996-2005), 4 (2006-2014). All models were reestimated using each cohort subgroup. The magnitude and pattern of effects were consistent across each cohort.
} 
in our primary analyses with the difference being the dependent variable specifications, which allowed for direct comparisons for the effects of risk preference on past political behavior relative to intent. Model estimates for these analyses are available in the Supplemental File. Overall, we found that risk preference was associated with lower intent to engage in future standard political behavior compared to past standard political behavior $(\beta \mathrm{s}=-.02$ to $-.06, p \mathrm{~s}<$ .002), meaning that risk preference was more strongly associated with behavior than intent. Similarly, greater risk preference was associated with lower intent to engage in social movement behavior $(\beta \mathrm{s}=-.06$ to $-.13, p \mathrm{~s}<.001)$ relative to past social movement behavior.

\section{Discussion}

Through examining links between adolescent risk preference and involvement in a wide range of political activities, this study contributes to a growing body of research suggesting that risk taking is a fundamental part of adolescent development that has negative as well as positive consequences for functioning (e.g., Do et al., 2017). Our findings indicated that youth with greater risk preference were more engaged in political activities, and these effects were particularly strong for social movement forms of involvement and among youth with at least some political interest. For social movement behaviors, this same pattern emerged for behavioral intentions, but risk preference was related to lower intent to donate and volunteer for political campaigns. Importantly, given our nationally representative sample, results are generalizable to graduating high school seniors in the U.S., and findings were significant after accounting for a wide array of covariates that lower the likelihood of alternative explanations for effects.

Consistent with hypotheses, greater risk preference was significantly associated with greater engagement in past social movement behaviors of protesting and boycotting as well as higher intentions to engage in these activities in the future. Individual differences in adolescent 
risk preferences are thought to encourage behaviors that are counter-normative (Jessor, 1987), which may be useful for social movement behaviors given that these activities often involve direct opposition to established norms, political and social institutions, or political authorities (Hart \& Gullan, 2010; McAdam, 1986). Although many counter-normative behaviors may be considered socially destructive, social movement action may reflect one way youth can express social opposition in a manner that contributes to democratic functioning and personal health (Ballard \& Ozer, 2016; Della Porta, 2009). Social movement activities such as boycotting and protesting entail voicing opposition to political authority or institutions and seek to promote social change (Merelman, 1985). Youth with greater risk preference may be drawn to boycotting and protesting as a means of engaging in unconventional political activities that provide opportunities to collectively oppose and possibly change established social structures. This interpretation is consistent with prior research that has found connections between sensation seeking and autonomous and iconoclastic self-descriptions (Chassin, Presson, \& Sherman, 1988) as well as engagement in constructive behaviors that intentionally violate social conventions, such as high-risk athletic activities (Hansen \& Breivik, 2001). Associations between risk preference and social movement behaviors had a notable effect size. In our nationally representative analyses, the standardized estimates for associations between risk preference and social movement behaviors were similar to organized activity involvement with regard to past behavior and intent. As a point of comparison, past research has identified organized activity involvement as one of the more robust predictors of future political engagement (e.g., Hart, Donnelly, Youniss, \& Atkins, 2007; Zaff et al., 2003). In fact, the majority of research on the predictors of youth political engagement focus on contextual factors. Our study is among the first 
to empirically demonstrate this strong association between risk preference and actual and intended social movement behaviors in adolescence.

We also found evidence that links between risk preference and social movement behavior were stronger among youth with higher levels of political interest. Notably, the effect of risk preference on past social movement behavior and intent was positive regardless of levels of political interest. In other words, political interest is not a necessary condition for risk preference to be linked with social movement engagement. Engaging in protesting and boycotting may offer youth opportunities to experience novelty, solidarity with their peers, deviation from social norms, and in some instances, potential danger, even for those who are not interested in politics. Yet, our results also show that political interest amplifies the association between risk preference and social movement behavior. Political interest may compel youth to act on their risk preference in the political domain, and these youth may receive additional rewards from social movement participation in the form of fulfilling perceived social obligations, pursuing intrinsic motivation, or supporting personal autonomy. Alternatively, risk preference may enable youth to act on their interests by becoming politically engaged, despite uncertainties and challenges to social movement involvement.

Associations between risk preference and political engagement were less consistent and weaker for standard political forms of participation relative to social movement participation. Specifically, we found that a greater risk preference was associated with a higher likelihood of having voted, donated to a campaign, and having written to government officials. Yet, these links were generally small and only significant if youth endorsed at least 'some' level of interest. We did not find any evidence that risk preference was related to volunteering for a political campaign, and this behavior demonstrated very low prevalence in our sample. These more 
limited associations between risk preference and standard political behaviors are most likely due to the higher levels and greater range of risks that come with social movement activities relative to other types of political engagement (McAdam, 1986; Santos \& VanDaalen, 2018). On the whole, voting, donating to campaigns, and communicating with government officials are behaviors that may not be seen as very risky for youth. Yet, youth who possess both higher risk preference and some political interest may be more likely to view electoral political behaviors as viable outlets for expressing their preferences.

One unexpected finding was that greater risk preference was associated with lower intent to donate or work for a political campaign among youth who had not yet participated in these behaviors. These links appeared consistent across political interest, yet the negative association between risk preference and donating to a campaign was especially strong for youth with no political interest. Potentially, adolescents evaluate the riskiness of standard political behaviors differently depending on whether they are considering current behavior or behavior in the future. When evaluating intent, youth may be considering whether they would engage in this behavior in adulthood. Involvement with political campaigns is more normative for adults. However, campaign involvement is far less normative in adolescence, and thus the actual behavior is potentially more appealing for youth with higher risk preference and political interest.

Additional analyses indicate that risk preference was more strongly associated with past standard political and social movement behavior relative to intent of engaging in these behaviors in the future. These findings further suggest that actual engagement in political actions may be riskier during late adolescence relative to intent to engage in these behaviors in the future. Given that sensation seeking peaks during late adolescence (Romer, 2010), risk preference may be more strongly connected to political engagement during late adolescence and less strongly 
connected to political engagement later in life. With age, youth may gain more experience with various forms of political activities thus making them less novel and more normative, overall decreasing the risks affiliated with participation. Future research is needed to further examine whether risk preference longitudinally predicts greater political engagement earlier in development.

\section{Limitations and Future Directions}

Strengths of the study include the large and nationally representative samples and some moderate effect sizes. However, findings should be taken in light of certain limitations. Data were cross-sectional and cannot be used to make causal inferences. Further, it is important to note that our measures assessed youths' current risk preference and past political behavior. Although we interpreted associations by prioritizing risk preference as conceptual antecedents of political engagement, it is possible that participation in political behavior increases risk preference by strengthening youth's appreciation for novel settings or positive emotional sensations they may experience through political engagement or by adding older individuals to one's network who may be engaged in risk taking. Thus, it is possible that political actions could have made youth more comfortable with risk. Future research should utilize longitudinal designs to elucidate the temporal sequencing between risk preference and political engagement over time.

Measures of political engagement were limited to four standard political and two social movement behaviors. Fruitful next steps for this line of research would include assessing a wider array of political and non-political behaviors (e.g., community service). Further, it is important to note that the risks affiliated with certain forms of political action such as activism may vary for youth from different racial, gender, or sexual backgrounds. Future research is needed to conduct 
more in-depth investigations of the conditions that risk preference motivate youth's engagement in civic life. Additionally, examining mediators of risk preference and youth's social movement actions-such as opposition to authority, critical worldview, or low adherence to social normscan add support for theoretical explanation regarding how risk preference may motivate political action.

Although the assessment of risk preference used in this study has been used in prior research and related in expected ways to other constructs such as substance use (e.g., Keyes et al., 2015), the two-item self-report measure may be limited in its ability to distinguish between willingness and desire to engage in risky behaviors. Whereas desire to engage in risky behaviors may entail affinity for risk and be more closely aligned with conceptualizations of sensation seeking, willingness to engage in risky behavior may be more aligned with tolerance for risk taking and conceptualizations of courage. Our findings may indicate that youth who prefer to engage in risky behaviors are more likely to protest or boycott because of the entailed risks. If our measures of risk preference also capture willingness to engage in risky behaviors, it is also possible that youth with higher risk preference are participating in protesting or boycotting despite the possible risks. Future research may benefit from examining links between diverse forms of risk preference (e.g., affinity versus tolerance of risk) and political engagement. Further, the self-report measure of risk preference used in this study may be subject to social desirability bias. Future research may benefit from assessing multiple indicators of risk preference, including behavioral tasks.

This study examined links between risk preference and political engagement among high school seniors, the majority of whom were 18 years of age. Increased adolescent risk taking is thought to begin in early to middle-adolescence (Steingberg, 2008). However, sensation seeking 
appears to peak around the ages of 17 and 18 years (Romer, 2010), when youth in the U.S. are experiencing large increases in autonomy through the acquisition of driving privileges and gain the ability to participate in certain forms of political action (i.e., voting). Further, some forms of political engagement may satisfy risk preference in adolescence but not in young adulthood or beyond after youth gain greater experience within the political system or political engagement becomes more normative. The coalescence between age-related changes in sensation seeking, increased autonomy, expanded political rights in the U.S., and the novelty of political engagement may make late adolescence a unique developmental period for linking risk preferences with political behavior.

Despite these limitations, establishing a link between risk preference and political engagement has important implications for theory on civic development. Specifically, we add to knowledge about adolescents' political engagement - an area where comprehensive theories are lacking (Sherrod \& Lauckhardt, 2009) by identifying risk preference as a correlate of political engagement, and one that appears to interact dynamically with political interest. Research on youth political engagement has generally focused on how positive community experiences promote assets conducive to democratic values and political participation (Zaff et al., 2010) and research using the positive youth development (PYD) model (Gestsdóttir \& Lerner, 2007) has highlighted that PYD is largely rooted in self-regulation and leads to greater civic engagement. Findings from this study highlight that risk preference, which is often considered to be antithetical to developmental assets including self-regulation, may be an alternative pathway to youth political engagement. These findings raise questions concerning whether various forms of civic engagement have different developmental origins or whether self-regulation and risk preferences differentially predict sustained versus episodic involvement. 
Our study also contributes to theory and research on adolescent risk taking, political engagement, and positive youth development by highlighting the importance of considering the adaptive role of adolescent risk preference. Our results add to the growing body of theory and research on adolescent risk taking as developmentally normative and adaptive (e.g., Do et al., 2017; Duell \& Steinberg, 2019) by raising questions as to whether political engagement may constitute positive risk taking. Recent theorizing proposes that positive risks must: (1) benefit adolescents' well-being, (2) have potential costs that are mild in severity relative to negative risk taking, (3) and be legal and socially acceptable. Although political behaviors have been connected with higher well-being (Sherrod \& Lauckhardt, 2009), may entail minor costs (e.g., Ballard \& Ozer, 2016), and are socially desirable (Galston, 2001), it is unclear whether all forms of political action meet these criteria and whether the costs and benefits of political action vary for youth from different racial, ethnic, sexual, or socioeconomic backgrounds. Thus, political engagement may represent one form of positive risk taking for some youth, yet careful consideration and examination of the context surrounding engagement is needed.

Findings also contribute to a growing body of literature on adolescents' political actions by suggesting that risk preference is a part of the constellation of factors that explain why some adolescents become politically active and others do not. Our findings also extend PYD theory and research, which to date has primarily examined relationships between supportive contexts, positive competencies, and positive contributions such as civic engagement (Lerner et al., 2005). The PYD model, although certainly not without utility, can be considered an instantiation of the balance principle in largely predicting that good things lead to more good things (Heider, 1958). Our research highlights risk preference as a factor that has typically been considered negatively 
for adolescents, but we now have evidence suggesting that risk preference is linked with a higher likelihood of youths' positive societal contributions in the political domain.

Our work may also help explain findings of other studies, which have shown a complex and sometime positive relationship between positive competencies and risk behaviors (LewinBizan et al., 2010; Phelps et al., 2007; Warren et al., 2016). Specifically, providing a conceptual and empirical link between risk preference and political engagement highlights that positive and constructive behaviors may also entail some degree of risk for youth and adolescents who have higher risk preference may express these tendencies in constructive and possibly destructive ways (Chassin et al., 1988). Building a framework that incorporates both positive and negative expressions of risk preference provides a more complete understanding of the nature of adolescent development. Regarding implications for practice, our findings suggest that political engagement may be a constructive and viable outlet for youth who prefer risk-taking. Providing greater opportunities for youth to become politically involved may support autonomy development and provide youth with a constructive context to have novel, complex, and potentially highly-emotional experiences. Some correlational research has suggested that youth with heightened risk preference may, in some cases, be more positively affected by contexts that promote positive development (Dever et al., 2012). Likewise, youth political activists are drawn into movements in part through their social networks (Hart \& Gullan, 2010; McAdam, 1986). The connection between risk preference and political engagement was generally stronger for youth with greater political interest, and prior experimental research has shown that political interest is modifiable within a lab-based setting (Robinson, 2017). Organizations seeking to increase youth political involvement may benefit from increasing youths' political interest, especially among those who have greater risk preference. 


\section{Conclusion}

Adolescent risk taking is often viewed as a public health concern that should be mitigated. However, heightened youth risk taking is also adaptive and can thus be expressed in developmentally positive ways. This study proposes that political engagement may offer a unique context that is appealing to or tolerated by youth with a strong risk preference and provides a potential avenue for adaptive risk-taking. Future research should continue to document the potentially positive nature and expression of adolescent risk preference and identify contexts that promote healthy and adaptive risk taking. 


\section{References}

Andolina, M. W., Jenkins, K., Zukin, C., \& Keeter, S. (2003). Habits from home, lessons from school: Influences on youth civic engagement. PS: Political Science \& Politics, 36, 275280. Doi: $10.1017 / \mathrm{S} 104909650300221 \mathrm{X}$

Ballard, P. J., Hoyt, L. T., \& Pachucki, M. C. (2018). Impacts of Adolescent and Young Adult Civic Engagement on Health and Socioeconomic Status in Adulthood. Child Development. Early view. Doi: 10.1111/cdev.12998.

Ballard, P. J., \& Ozer, E. (2016). The implications of youth activism for health and well-being. In J. O. Conner \& S.M. Rosen (Eds.), Contemporary youth activism: Advancing social justice in the United States. Santa Barbara, CA: Praeger

Barkley-Levenson, E. E., Van Leijenhorst, L., \& Galván, A. (2013). Behavioral and neural correlates of loss aversion and risk avoidance in adolescents and adults. Developmental Cognitive Neuroscience, 3, 72-83. Doi: 10.1016/j.dcn.2012.09.007.

Benjamini, Y., \& Hochberg, Y. (1995). Controlling the false discovery rate: a practical and powerful approach to multiple testing. Journal of the Royal Statistical Society. Series B (Methodological), 57, 289-300. Doi: 10.2307/2346101.

Chassin, L., Hussong, A., Barrera, M., Jr., Molina, B., Trim, R., \& Ritter, J. (2004). Adolescent substance use. In R. Lerner \& L. Steinberg (Eds.), Handbook of adolescent psychology (2nd ed., pp. 665-696). New York: Wiley.

Chassin, L., Presson, C. C., \& Sherman, S. J. (1988). “Constructive” vs. "destructive” deviance in adolescent health-related behaviors. Journal of Youth and Adolescence, 18, 245-262. Doi: 10.1007/BF02139039. 
Costanza-Chock, S. (2012). Youth and social movements: Key lessons for allies. Berkman Center Research Publication No. 2013-13. Doi: 10.2139/ssrn.2199531.

Dahl, R. E. (2004). Adolescent brain development: A period of vulnerabilities and opportunities. Keynote address. Annals of the New York Academy of Sciences, 1021, 1-22. Doi: 10.1196/annals.1308.001.

Deci, E. L., \& Ryan, R. M. (2008). Self-determination theory: A macrotheory of human motivation, development, and health. Canadian Psychology, 49, 182-185. Doi: 10.1037/a0012801.

Delgado, M. (2015). Community practice and urban youth: Social justice service-learning and civic engagement. New York: Routledge.

Della Porta, D. (2009). Democracy in social movements. New York, NY, USA: Palgrave Macmillan.

Dever, B. V., Schulenberg, J. E., Dworkin, J. B., O’Malley, P. M., Kloska, D. D., \& Bachman, J. G. (2012). Predicting risk-taking with and without substance use: The effects of parental monitoring, school bonding, and sports participation. Prevention Science, 13, 605-615. Doi: 10.1007/s11121-012-0288-z.

Do, K. T., Moreira, J. F. G., \& Telzer, E. H. (2017). But is helping you worth the risk? Defining prosocial risk taking in adolescence. Developmental Cognitive Neuroscience, 25, 260271. Doi: $10.1016 /$ j.den.2016.11.008.

Duell, N., \& Steinberg, L. (2019). Positive risk taking in adolescence. Child Development Perspectives, 13, 48-52. Doi: 10.1111/cdep.12310.

Ekman, J., \& Amnå, E. (2012). Political participation and civic engagement: Towards a new typology. Human Affairs, 22, 283-300. Doi: 10.2478/s13374-012-0024-1. 
File, T. (2014). Young-adult voting: An analysis of presidential elections, 1964-2012.

Washington, DC: U.S. Census Bureau, Department of Commerce.

Galston, W. A. (2001). Political knowledge, political engagement, and civic education. Annual Review of Political Science, 4, 217-234. Doi: 10.1146/annurev.polisci.4.1.217

Gestsdóttir, S., \& Lerner, R. M. (2007). Intentional self-regulation and positive youth development in early adolescence: Findings from the 4-h study of positive youth development. Developmental Psychology, 43, 508-521. Doi: 10.1037/00121649.43.2.508.

Gordon, H. R., \& Taft, J. K. (2011). Rethinking youth political socialization: Teenage activists talk back. Youth \& Society, 43, 1499-1527. Doi: 10.1177/0044118X10386087.

Hansen, E. B., \& Breivik, G. (2001). Sensation seeking as a predictor of positive and negative risk behaviour among adolescents. Personality and Individual Differences, 30, 627-640. Doi: 10.1016/S0191-8869(00)00061-1.

Hansen, D. M., \& Larson, R. W. (2007). Amplifiers of developmental and negative experiences in organized activities: Dosage, motivation, lead roles, and adult-youth ratios. Journal of Applied Developmental Psychology, 28, 360-374. Doi: 10.1016/j.appdev.2007.04.006.

Hart, D., Donnelly, T. M., Youniss, J., \& Atkins, R. (2007). High school community service as a predictor of adult voting and volunteering. American Educational Research Journal, 44, 197-219. Doi: 10.3102/0002831206298173.

Hart, D., \& Gullan, R. L. (2010). The sources of adolescent activism: Historical and contemporary findings. In L.R. Sherrod, J. Torney-Purta, \& C.A. Flanagan (Eds.), Handbook of research on civic engagement in youth (pp. 67-90).John Wiley \& Sons. Heider, F. (1958). The Psychology of Interpersonal Relations. John Wiley \& Sons. 
Hope, E. C., Keels, M., \& Durkee, M. I. (2016). Participation in Black Lives Matter and deferred action for childhood arrivals: Modern activism among Black and Latino college students. Journal of Diversity in Higher Education, 9, 203-215. Doi: 10.1037/dhe0000032.

Jessor, R. (1987). Problem-behavior theory, psychosocial development, and adolescent problem drinking. British Journal of Addiction, 82, 331-342. Doi: 10.1111/j.13600443.1987.tb01490.x.

Johnston, L.D., O’Malley, P.M., Bachman, J.G., \& Schulenberg, J.E. (2012). Monitoring the Future national results on adolescent drug use: Overview of key findings. Ann Arbor: Institute for Social Research, The University of Michigan

Keyes, K. M., Jager, J., Hamilton, A., O’Malley, P. M., Miech, R., \& Schulenberg, J. E. (2015). National multi-cohort time trends in adolescent risk preference and the relation with substance use and problem behavior from 1976 to 2011. Drug and Alcohol Dependence, 155, 267-274. Doi: 10.1016/j.drugalcdep.2015.06.031.

Lerner, R. M., Lerner, J. V., Almerigi, J. B., Theokas, C., Phelps, E., Gestsdottir, S., ... \& Smith, L. M. (2005). Positive youth development, participation in community youth development programs, and community contributions of fifth-grade adolescents: Findings from the first wave of the 4-H study of positive youth development. The Journal of Early Adolescence, 25, 17-71. Doi: 10.1177/0272431604272461.

Lewin-Bizan, S., Lynch, A. D., Fay, K., Schmid, K., McPherran, C., Lerner, J. V., \& Lerner, R. M. (2010). Trajectories of positive and negative behaviors from early-to middleadolescence. Journal of Youth and Adolescence, 39, 751-763. Doi:10.1007/s10964010-9532-7. 
Li, C. H. (2014). The performance of MLR, USLMV, and WLSMV estimation in structural regression models with ordinal variables. East Lansing, MI, USA: Michigan State University Retrieved from http:/gradworks.umi.com/36/20/3620406.html ProQuest database.

Mannheim, K. (1952). The problem of generations. In P. Kecskemeti (Ed.), Essays on the Sociology of Knowledge (pp. 276-320), London: Routledge and Kegan Paul.

McAdam, D. (1986). Recruitment to high-risk activism: The case of freedom summer. American Journal of Sociology, 92, 64-90. Doi: 10.1086/228463.

McIntosh, H., Hart, D., \& Youniss, J. (2007). The influence of family political discussion on youth civic development: Which parent qualities matter?. PS: Political Science \& Politics, 40, 495-499. Doi: 10.1017/S1049096507070758.

Merelman, R. M. (1985). Role and personality among adolescent political activists. Youth \& Society, 17, 37-68. Doi: 10.1177/0044118X85017001003.

Metzger, A., Alvis, L. M., Oosterhoff, B., Babskie, E., Syvertsen, A., \& Wray-Lake, L. (2018). The intersection of emotional and sociocognitive competencies with civic engagement in middle childhood and adolescence. Journal of Youth and Adolescence, 47, 1-21. Doi: 10.1007/s10964-018-0842-5.

Metzger, A., Ferris, K. A., \& Oosterhoff, B. (2018). Adolescents' civic engagement: Concordant and longitudinal associations among civic beliefs and civic involvement. Journal of Research on Adolescence. Early view. Doi: 10.1111/jora.12423.

Metzger, A., Oosterhoff, B., Palmer, C. A., \& Ferris, K. (2014). Dimensions of citizenship: Associations among adolescents' sociopolitical values and civic judgments. PS: Political Science \& Politics, 47, 443-448. Doi: 10.1017/S1049096514000365. 
Metzger, A., \& Smetana, J. G. (2009). Adolescent civic and political engagement: Associations between domain-specific judgments and behavior. Child Development, 80, 433-441. Doi: 10.1111/j.1467-8624.2009.01270.x.

Norris, P. (2004). Young people \& political activism. Harvard University, John F. Kennedy School of Government. Retrieved from https://sites.hks.harvard.edu/fs/pnorris/Acrobat/COE.pdf

Oosterhoff, B., Kaplow, J. B., Layne, C. M., \& Pynoos, R. S. (2018). Civilization and its discontented: Links between youth victimization, beliefs about government, and political participation across seven American presidencies. American Psychologist, 73, 230-242. Doi: $10.1037 / \mathrm{amp} 0000189$.

Pharo, H., Sim, C., Graham, M., Gross, J., \& Hayne, H. (2011). Risky business: Executive function, personality, and reckless behavior during adolescence and emerging adulthood. Behavioral Neuroscience, 125, 970-978. Doi: 10.1037/a0025768.

Phelps, E., Balsano, A. B., Fay, K., Peltz, J. S., Zimmerman, S. M., Lerner, R. M. (2007). Nuances in early adolescent developmental trajectories of positive and problematic/risk behaviors: Findings from the 4-H Study of Positive Youth Development. Child and Adolescent Psychiatric Clinics of North America, 165, 473-496.

Doi:10.1016/j.chc.2006.11.006.

Quinn, P. D., \& Harden, K. P. (2013). Differential changes in impulsivity and sensation seeking and the escalation of substance use from adolescence to early adulthood. Development and Psychopathology, 25, 223-239. Doi: 10.1017/S0954579412000284.

Rao, U., Sidhartha, T., Harker, K. R., Bidesi, A. S., Chen, L. A., \& Ernst, M. (2011). Relationship between adolescent risk preferences on a laboratory task and behavioral 
measures of risk-taking. Journal of Adolescent Health, 48, 151-158. Doi:

10.1016/j.jadohealth.2010.06.008

Robison, J. (2017). The social rewards of engagement: Appealing to social motivations to stimulate political interest at high and low levels of external efficacy. Political Studies, 65, 24-41. Doi: 10.1177/0032321715619431.

Romer, D. (2010). Adolescent risk taking, impulsivity, and brain development: Implications for prevention. Developmental Psychobiology: The Journal of the International Society for Developmental Psychobiology, 52, 263-276. Doi: 10.1002/dev.20442.

Ryder, N. B. (1965). The cohort as a concept in the study of social change. American Sociological Review, 30, 843-861. Doi: 10.2307/2090964.

Santos, C. E., \& VanDaalen, R. A. (2018). Associations among psychological distress, high-risk activism, and conflict between ethnic-racial and sexual minority identities in lesbian, gay, bisexual racia/ethnic minority adults. Journal of Counseling Psychology, 65, 194-203. Doi: $10.1037 / \operatorname{cou} 0000241$.

Šerek, J., Machackova, H., \& Macek, P. (2018). Who crosses the norms? Predictors of the readiness for non-normative political participation among adolescents. Journal of Adolescence, 62, 18-26. Doi: 10.1016/j.adolescence.2017.11.001.

Sherrod, L., \& Lauchardt, J. (2009). The development of citizenship. In R. M. Lerner, \& L. Steinberg (eds.), Handbook of adolescent psychology (3rd ed ). Contextual influences on adolescent development, Vol. 2. (pp. 372-407). New York: Wiley \& Sons.

Smith, A. (2013). Civic engagement in the digital age. Washington, DC: Pew Research Center. Steinberg, L. (2004). Risk taking in adolescence: What changes, and why?. Annals of the New York Academy of Sciences, 1021, 51-58. Doi: 10.1196/annals.1308.005. 
Steinberg, L. (2007). Risk taking in adolescence: New perspectives from brain and behavioral science. Current Directions in Psychological Science, 16, 55-59. Doi: 10.1111/j.14678721.2007.00475.x.

Steinberg, L. (2008). A social neuroscience perspective on adolescent risk-taking. Developmental Review, 28, 78-106. Doi: 10.1016/j.dr.2007.08.002.

Strang, N. M., Chein, J. M., \& Steinberg, L. (2013). The value of the dual systems model of adolescent risk-taking. Frontiers in Human Neuroscience, 7, 1-4. Doi: 10.3389/fnhum.2013.00223.

Syvertsen, A. K., Wray-Lake, L., Flanagan, C. A., Briddell, L., \& Osgood, D. W. (2011). Thirtyyear trends in U.S. adolescents' civic engagement: A story of changing participation and educational differences. Journal of Research on Adolescence, 21, 586-594. Doi: 10.1111/j.1532-7795.2010.00706.x.

Verba, S., Schlozman, K. L., \& Brady, H. E. (1995). Voice and equality: Civic voluntarism in American politics. Cambridge, MA: Harvard University Press.

Warren, M.T., Wray-Lake, L., Rote, W., \& Shubert, J. (2016). Thriving while experimenting with risk? Examining trajectories of adaptive functioning, delinquency, and substance use in a nationally representative sample of U.S. adolescents. Developmental Psychology, 52, 296-310. Doi: 10.1037/a0039922.

Watts, R. J., \& Flanagan, C. (2007). Pushing the envelope on youth civic engagement: A developmental and liberation psychology perspective. Journal of Community Psychology, 35, 779-792. Doi: 10.1002/jcop.20178. 
Weber, E. U., Blais, A. R., \& Betz, N. E. (2002). A domain-specific risk-attitude scale: Measuring risk perceptions and risk behaviors. Journal of Behavioral Decision Making, 15, 263-290. Doi: 10.1002/bdm.414.

Wray-Lake, L., \& Sloper, M. A. (2016). Investigating general and specific links from adolescents' perceptions of ecological assets to their civic actions. Applied Developmental Science, 20, 250-266. Doi: 10.1080/10888691.2015.1114888.

Zaff, J. F., Hart, D., Flanagan, C. A., Youniss, J., \& Levine, P. (2010). Developing civic engagement within a civic context. In R. M. Lerner, M. E. Lamb, \& A. M. Freund (eds.), The handbook of life-span development. Social and emotional development, Vol. 2 (pp. 590-630). Hoboken, NJ: Wiley.

Zaff, J. F., Moore, K. A., Papillo, A. R., \& Williams, S. (2003). Implications of extracurricular activity participation during adolescence on positive outcomes. Journal of Adolescent Research, 18, 599-630. Doi: 10.1177/0743558403254779. 
Table 1.

Descriptive Statistics and Bivariate Correlations among Study Variables

\begin{tabular}{|c|c|c|c|c|c|c|c|c|c|c|c|c|c|c|c|c|c|c|c|c|c|c|c|c|c|c|}
\hline & $\begin{array}{l}\mathrm{M} \\
(\mathrm{N})\end{array}$ & $\begin{array}{l}\text { SD } \\
(\%)\end{array}$ & 2 & 3 & 4 & 5 & 6 & 7 & 8 & 9 & 10 & 11 & 12 & 13 & 14 & 15 & 16 & 17 & 18 & 19 & 20 & 21 & 22 & 23 & 24 & 25 \\
\hline 1. Age $(18+)$ & & & $-.04 *$ & $-.29^{*}$ & $-.16^{*}$ & $-.09 *$ & $-.04 *$ & $-.49 *$ & $-.02 *$ & .00 & $-.03 *$ & .00 & $-.03^{*}$ & $-.08^{*}$ & .01 & -.01 & .01 & $.08^{*}$ & $.06^{*}$ & $-.06^{*}$ & $.10^{*}$ & $.02 *$ & $.03 *$ & .01 & -.01 & .00 \\
\hline 2. Gender (female) & & & & -.01 & .01 & $-.04 *$ & $.09 *$ & .01 & .00 & $.11 *$ & $.12 *$ & $-.15^{*}$ & $.17^{*}$ & $.10^{*}$ & $.07 *$ & $-.18 *$ & $-.23 *$ & $-.14 *$ & $-.14 *$ & $-.24 *$ & $-.07 *$ & $-.10 *$ & .00 & -.01 & -.01 & $-.02 *$ \\
\hline 3. Black & & & & & $-.08 *$ & $.14 *$ & $-.03 *$ & $.61 *$ & $.04 *$ & $-.02 *$ & $.01 *$ & $.04 *$ & -.01 & $.07 *$ & $-.09 *$ & $-.02 *$ & $-.05 *$ & $-.07 *$ & $-.05 *$ & $.08 *$ & $.05^{*}$ & -.01 & $-.03 *$ & .00 & $.02 *$ & .01 \\
\hline 4. Hispanic & & & & & & $-.13 *$ & $.05 *$ & $.29 *$ & $.02 *$ & $-.03 *$ & $-.03 *$ & $-.03 *$ & $-.03 *$ & .01 & $-.03 *$ & .00 & .00 & $-.07 *$ & $-.03 *$ & $.03 *$ & $-.03 *$ & $-.02 *$ & $-.02 *$ & $-.04 *$ & $-.02 *$ & -.01 \\
\hline 5. Parents' Edu & 3.75 & 1.21 & & & & & $.02 *$ & $.14 *$ & -.01 & $.05^{*}$ & $.10^{*}$ & $.15^{*}$ & $.14 *$ & $.13 *$ & $.08 *$ & $-.10 *$ & $-.02 *$ & .01 & $.13^{*}$ & $.06 *$ & $.05^{*}$ & $.02 *$ & $.06^{*}$ & $.09 *$ & $.09 *$ & $.07 *$ \\
\hline 6. Political Ideology & 3.04 & .97 & & & & & & .01 & -.01 & $.03 *$ & $.03 *$ & $-.08 *$ & -.01 & $-.03 *$ & $-.14 *$ & $.02 *$ & $.04 *$ & $.12 *$ & $-.02 *$ & $.07 *$ & $-.04 *$ & .01 & .01 & $.02 *$ & $.07 *$ & $.06 *$ \\
\hline 7. Cohort & 2.30 & 1.11 & & & & & & & $-.05 *$ & $-.03 *$ & $.02 *$ & $.04 *$ & .00 & $.11^{*}$ & $-.07 *$ & .01 & $-.02 *$ & $-.18 *$ & $-.10^{*}$ & $.13^{*}$ & $.05^{*}$ & $-.04 *$ & $-.07 *$ & $-.03 *$ & $.02 *$ & .01 \\
\hline 8. Election Year & (28363) & (25.9) & & & & & & & & -.01 & .01 & .01 & .01 & .01 & .01 & .00 & .00 & .00 & .01 & .00 & $.07 *$ & .00 & $.02 *$ & .00 & .00 & .00 \\
\hline 9. Clubs & 1.56 & 1.17 & & & & & & & & & $.17 *$ & $.12 *$ & $.28 *$ & $.14 *$ & $.06 *$ & .00 & $-.02 *$ & $-.05 *$ & $.08 *$ & $-.04 *$ & $.02 *$ & $.04 *$ & $.05^{*}$ & $.06 *$ & $.05 *$ & $.05 *$ \\
\hline 10. Arts & 2.02 & 1.53 & & & & & & & & & & $.04 *$ & $.29 *$ & $.20 *$ & $.12 *$ & -.01 & $-.07 *$ & $-.15^{*}$ & $.09^{*}$ & $-.06 *$ & $.02 *$ & $.04 *$ & $.04 *$ & .08 & $.08^{*}$ & $.07 *$ \\
\hline 11. Athletic & 2.62 & 1.71 & & & & & & & & & & & $.31 *$ & $.13 *$ & $.11 *$ & $.02 *$ & $.02 *$ & .01 & $.06 *$ & $.07 *$ & $.04 *$ & .00 & $.02 *$ & $.03 *$ & $-.02 *$ & .00 \\
\hline 12. Other & 2.74 & 1.53 & & & & & & & & & & & & $.38 *$ & $.18 *$ & $-.04 *$ & $-.12 *$ & $-.17 *$ & $.17 *$ & $-.09 *$ & $.03 *$ & $.05^{*}$ & $.08 *$ & $.12 *$ & $.08 *$ & $.07 *$ \\
\hline 13. Com Service & 2.13 & 1.01 & & & & & & & & & & & & & $.23 *$ & .00 & $-.10 *$ & $-.18 *$ & $.15^{*}$ & $-.04 *$ & $.05^{*}$ & $.07 *$ & $.08^{*}$ & $.12 *$ & $.09 *$ & $.08 *$ \\
\hline 14. Religious Ser Att. & 2.76 & 1.11 & & & & & & & & & & & & & & $-.06 *$ & $-.11 *$ & $-.20 *$ & $.07 *$ & $-.12 *$ & $.02 *$ & .00 & $.04 *$ & $.04 *$ & .01 & -.01 \\
\hline 15. Victimization & 1.39 & .52 & & & & & & & & & & & & & & & $.47 *$ & $.21 *$ & $.03 *$ & $.20 *$ & $.03 *$ & $.06^{*}$ & $.04 *$ & $.05 *$ & $.09 *$ & $.08 *$ \\
\hline 16. Delinquency & 1.25 & .41 & & & & & & & & & & & & & & & & $.38 *$ & $-.07 *$ & $.27 *$ & $.02 *$ & $.04 *$ & $.03 *$ & .01 & $.06^{*}$ & $.07 *$ \\
\hline 17. Substance Use & 2.98 & 1.85 & & & & & & & & & & & & & & & & & -.01 & $.26 *$ & .00 & $.03 *$ & $.03 *$ & $.02 *$ & $.04 *$ & $.05 *$ \\
\hline 18. Political Interest & 3.05 & .99 & & & & & & & & & & & & & & & & & & .00 & $.09 *$ & $.10^{*}$ & $.12 *$ & $.17 *$ & $.15^{*}$ & $.12 *$ \\
\hline 19. Risk Taking & 3.07 & 1.20 & & & & & & & & & & & & & & & & & & & $.03 *$ & .01 & .00 & $.02 *$ & $.05^{*}$ & $.05^{*}$ \\
\hline 20. Vote & (7961) & (7.3) & & & & & & & & & & & & & & & & & & & & $.10^{*}$ & $.09^{*}$ & $.12 *$ & $.08 *$ & $.09 *$ \\
\hline 21. Donate to Camp & $(3550)$ & $(3.2)$ & & & & & & & & & & & & & & & & & & & & & $.22 *$ & $.19^{*}$ & $.15^{*}$ & $.18 *$ \\
\hline 22. Work for Camp & (5014) & $(4.6)$ & & & & & & & & & & & & & & & & & & & & & & $.17 *$ & $.14 *$ & $.20 *$ \\
\hline 23. Write Gov & (11317) & $(10.5)$ & & & & & & & & & & & & & & & & & & & & & & & $.21 *$ & $.21 *$ \\
\hline 24. Boycott & (7858) & (7.3) & & & & & & & & & & & & & & & & & & & & & & & & $.33 *$ \\
\hline 25. Protest & $(3896)$ & (3.6) & & & & & & & & & & & & & & & & & & & & & & & & \\
\hline
\end{tabular}

Notes: $* p<.05$. Edu $=$ Education. Election Year coded $0=$ non-election year, $1=$ election year. Age coded $0=$ under $18,1=$ over 18. Com $=$ Community. Ser. Att. $=$ Service Attendance. Camp $=$ Campaign. Gov $=$ Government. 
Table 2

Standardized Estimates, Unstandardized Estimates, and Standard Errors for Regression Models Predicting Standard Political Behavior

\begin{tabular}{|c|c|c|c|c|c|c|c|c|c|c|c|c|}
\hline & \multicolumn{3}{|c|}{ Vote } & \multicolumn{3}{|c|}{ Donate to Campaign } & \multicolumn{3}{|c|}{ Work for a Campaign } & \multicolumn{3}{|c|}{ Write Government } \\
\hline & Stand. Est. & Est. & $S E$ & Stand. Est. & Est. & $S E$ & Stand. Est. & Est. & $S E$ & Stand. Est. & Est. & $S E$ \\
\hline Age & $.296^{*}$ & .777 & .021 & $.056^{*}$ & .147 & .021 & $.072 *$ & .190 & .019 & $.012 *$ & .032 & .014 \\
\hline Female & $-.125 *$ & -.251 & .012 & $-.022 *$ & -.043 & .015 & -.005 & -.010 & .013 & $-.016^{*}$ & -.032 & .010 \\
\hline Black & $.088^{*}$ & .244 & .015 & $-.024 *$ & -.069 & .023 & $-.072 *$ & -.199 & .022 & -.006 & -.015 & .015 \\
\hline Hispanic & $-.055^{*}$ & -.287 & .038 & $-.045 *$ & -.239 & .051 & $-.065^{*}$ & -.343 & .048 & $-.078 *$ & -.412 & .036 \\
\hline Parents' Education & $.094 *$ & .078 & .005 & $.057 *$ & .047 & .006 & $.134 *$ & .111 & .005 & $.146^{*}$ & .121 & .004 \\
\hline Political Ideology & $-.065^{*}$ & -.067 & .006 & $.024 *$ & .025 & .008 & .008 & .009 & .007 & $.026^{*}$ & .026 & .006 \\
\hline Cohort & $.086^{*}$ & .077 & .005 & $-.093 *$ & -.084 & .006 & $-.148^{*}$ & -.133 & .006 & $-.047 *$ & -.043 & .005 \\
\hline Election Year & $.126^{*}$ & .287 & .012 & .009 & .020 & .017 & $.033 *$ & .075 & .015 & .005 & .011 & .012 \\
\hline Clubs & $.029 *$ & .025 & .006 & $.095^{*}$ & .081 & .008 & $.096^{*}$ & .082 & .007 & $.087 *$ & .074 & .005 \\
\hline Arts & $.041^{*}$ & .027 & .005 & $.092 *$ & .060 & .006 & $.088^{*}$ & .057 & .006 & $.128 *$ & .084 & .004 \\
\hline Athletic & $.076^{*}$ & .045 & .004 & .008 & .005 & .006 & $.057^{*}$ & .033 & .006 & $.055^{*}$ & .032 & .004 \\
\hline Other & $.058^{*}$ & .038 & .005 & $.137^{*}$ & .089 & .006 & $.186^{*}$ & .121 & .006 & $.196^{*}$ & .128 & .004 \\
\hline Community Service & $.087 *$ & .086 & .005 & $.143^{*}$ & .141 & .007 & $.164 *$ & .161 & .006 & $.190 *$ & .187 & .005 \\
\hline volvement & $.031^{*}$ & .028 & .005 & .007 & .007 & .007 & $.079 *$ & .071 & .006 & $.069 *$ & .062 & .005 \\
\hline Victimization & $.058^{*}$ & .112 & .010 & $.109 *$ & 211 & .013 & $.072 *$ & .139 & .012 & $.074 *$ & .145 & .010 \\
\hline Delinquency & $.035^{*}$ & .085 & .010 & $.077 *$ & .185 & .015 & $.047 *$ & .113 & .014 & $.017^{*}$ & .040 & .012 \\
\hline Substance Use & .004 & .002 & .003 & $.067 *$ & .036 & .004 & .062 & .033 & .004 & $.027 *$ & .015 & .003 \\
\hline Political Interest & $.167^{*}$ & .168 & .005 & $.237 *$ & .239 & .006 & $.246^{*}$ & .248 & .006 & $.282 *$ & .284 & .005 \\
\hline Risk Preference & $.046 *$ & .039 & .005 & $.028 *$ & .024 & .006 & -.004 & -.003 & .006 & $.031 *$ & .026 & .004 \\
\hline Risk Preference $\mathrm{x}$ Interest & $.026 *$ & .021 & .004 & $.018 *$ & .014 & .005 & .002 & .001 & .005 & $.028 *$ & .022 & .004 \\
\hline$R^{2}$ & \multicolumn{3}{|c|}{.18} & \multicolumn{3}{|c|}{.15} & \multicolumn{3}{|c|}{.19} & \multicolumn{3}{|c|}{.22} \\
\hline$N$ & \multicolumn{3}{|c|}{109574} & \multicolumn{3}{|c|}{109574} & \multicolumn{3}{|c|}{109574} & \multicolumn{3}{|c|}{109574} \\
\hline
\end{tabular}

Notes: $* p<.05$ for covariates and $p<$ FDR adjusted $q$ for the main and interactive effect of risk preference (estimates available in the supplemental file). Stand.

$=$ Standardized. Est $=$ Estimate. $\mathrm{SE}=$ Standard Error. Age coded $0=$ under $18,1=$ over 18 . 
Table 3

Standardized Estimates, Unstandardized Estimates, and Standard Errors for Regression Models Predicting Standard Political Int ent among Youth who have not yet Participated

\begin{tabular}{|c|c|c|c|c|c|c|c|c|c|c|c|c|}
\hline & \multicolumn{3}{|c|}{ Vote } & \multicolumn{3}{|c|}{ Donate to Campaign } & \multicolumn{3}{|c|}{ Work for a Campaign } & \multicolumn{3}{|c|}{ Write Government } \\
\hline & Stand. Est. & Est. & $S E$ & Stand. Est. & Est. & $S E$ & Stand. Est. & Est. & $S E$ & Stand. Est. & Est. & $S E$ \\
\hline Age & $.011^{*}$ & .029 & .013 & $.046^{*}$ & .121 & .013 & $.052^{*}$ & .136 & .015 & $.106^{*}$ & .277 & .013 \\
\hline Female & $.018 *$ & .037 & .010 & $.026 *$ & .052 & .009 & $.043 *$ & .086 & .011 & $-.056 *$ & -.111 & .009 \\
\hline Black & $-.016 *$ & -.045 & .016 & $-.027 *$ & -.075 & .014 & $-.069 *$ & -.189 & .018 & $-.139 *$ & -.386 & .015 \\
\hline Hispanic & $-.091 *$ & -.472 & .034 & $-.028 *$ & -.146 & .028 & $-.016^{*}$ & -.084 & .033 & $-.054 *$ & -.277 & .028 \\
\hline Parents' Education & $.238^{*}$ & .197 & .004 & $.105^{*}$ & .087 & .004 & $.067 *$ & .056 & .004 & $.094 *$ & .078 & .004 \\
\hline Political Ideology & $.012 *$ & .013 & .007 & $-.023 *$ & -.024 & .005 & $.013 *$ & .013 & .006 & .006 & .006 & .005 \\
\hline Cohort & $-.088 *$ & -.079 & .004 & $-.082 *$ & -.074 & .004 & $-.087 *$ & -.078 & .005 & $-.177 *$ & -.159 & .004 \\
\hline Election Year & $.031 *$ & .071 & .011 & $.031 *$ & .070 & .010 & $.035^{*}$ & .081 & .012 & $.020 *$ & .046 & .010 \\
\hline Clubs & $.086^{*}$ & .074 & .006 & $.072 *$ & .062 & .005 & $.122 *$ & .105 & .006 & $.100 *$ & .086 & .005 \\
\hline Arts & $.127 *$ & .083 & .004 & $.068 *$ & .044 & .004 & $.101^{*}$ & .066 & .005 & $.109 *$ & .072 & .004 \\
\hline Athletic & $.164 *$ & .096 & .004 & $.066^{*}$ & .038 & .004 & $.037 *$ & .022 & .004 & $.046^{*}$ & .027 & .004 \\
\hline Other & $.248 *$ & .162 & .004 & $.162 *$ & .106 & .004 & $.218^{*}$ & .142 & .005 & $.185^{*}$ & .122 & .004 \\
\hline Community Service & $.156^{*}$ & .155 & .004 & $.136^{*}$ & .135 & .005 & $.172 *$ & .171 & .005 & $.169 *$ & .169 & .004 \\
\hline Religious Involvement & $.147 *$ & .132 & .004 & $.083 *$ & .075 & .004 & $.079 *$ & .071 & .005 & $.079 *$ & .071 & .004 \\
\hline Victimization & $-.053 *$ & -.104 & .009 & $.009 *$ & .019 & .009 & $.049 *$ & .096 & .010 & $.071 *$ & .140 & .009 \\
\hline Delinquency & $-.116^{*}$ & -.282 & .010 & $-.031 *$ & -.077 & .011 & .000 & .001 & .012 & .001 & .002 & .011 \\
\hline Substance Use & $.035^{*}$ & .019 & .003 & .000 & .000 & .003 & $-.035^{*}$ & -.019 & .003 & -.001 & .000 & .002 \\
\hline Political Interest & $.397 *$ & .404 & .004 & $.280 *$ & .285 & .004 & $.349 *$ & .355 & .004 & $.394 *$ & .404 & .004 \\
\hline Risk Preference & -.001 & -.001 & .004 & $-.028 *$ & -.023 & .004 & $-.025 *$ & -.021 & .005 & -.005 & -.004 & .004 \\
\hline Risk Preference $\mathrm{x}$ Interest & $.011 *$ & .009 & .003 & .006 & .005 & .004 & $.009 *$ & .008 & .004 & .005 & .004 & .004 \\
\hline$R^{2}$ & \multicolumn{3}{|c|}{.40} & \multirow{2}{*}{\multicolumn{3}{|c|}{.16}} & \multirow{2}{*}{\multicolumn{3}{|c|}{.25}} & \multirow{2}{*}{\multicolumn{3}{|c|}{$\begin{array}{c}.30 \\
96620\end{array}$}} \\
\hline$N$ & & 182 & & & & & & & & & & \\
\hline
\end{tabular}

Notes: $* p<.05$ for covariates and $p<$ FDR adjusted $q$ for the main and interactive effect of risk preference (estimates available in the supplemental file). Stand. $=$ Standardized. Est $=$ Estimate. $\mathrm{SE}=$ Standard Error. Age $\operatorname{coded} 0=$ under $18,1=$ over 18. 
Table 4

Standardized Estimates, Unstandardized Estimates, and Standard Errors for Regression Models Predicting Social Movement Behaviors

\begin{tabular}{|c|c|c|c|c|c|c|}
\hline & \multicolumn{3}{|c|}{ Boycott } & \multicolumn{3}{|c|}{ Protest } \\
\hline & Stand. Est. & Est. & $S E$ & Stand. Est. & Est. & $S E$ \\
\hline Age & $-.026^{*}$ & -.068 & .015 & -.009 & -.024 & .019 \\
\hline Female & -.011 & -.022 & .012 & $-.047 *$ & -.093 & .015 \\
\hline Black & $.037 *$ & .103 & .017 & $.016^{*}$ & .044 & .021 \\
\hline Hispanic & $-.051 *$ & -.265 & .038 & $-.031 *$ & -.163 & .047 \\
\hline Parents' Education & $.172 *$ & .142 & .005 & $.156^{*}$ & .129 & .006 \\
\hline Political Ideology & $.119^{*}$ & .123 & .006 & $.124 *$ & .128 & .007 \\
\hline Cohort & $.036^{*}$ & .032 & .005 & $.016^{*}$ & .014 & .007 \\
\hline Election Year & -.005 & -.010 & .013 & -.002 & -.003 & .016 \\
\hline Clubs & $.086^{*}$ & .074 & .006 & $.093^{*}$ & .080 & .007 \\
\hline Arts & $.124 *$ & .081 & .004 & $.144 *$ & .094 & .005 \\
\hline Athletic & $-.030 *$ & -.017 & .004 & .001 & .000 & .005 \\
\hline Other & $.135^{*}$ & .088 & .005 & $.145^{*}$ & .095 & .006 \\
\hline Community Service & $.152 *$ & .149 & .005 & $.167 *$ & .165 & .006 \\
\hline Religious Involvement & .002 & .002 & .005 & -.009 & -.008 & .007 \\
\hline Victimization & $.133^{*}$ & .257 & .010 & $.145^{*}$ & .281 & .011 \\
\hline Delinquency & $.096^{*}$ & .230 & .011 & $.114 *$ & .273 & .014 \\
\hline Substance Use & $.070^{*}$ & .038 & .003 & $.107^{*}$ & .058 & .004 \\
\hline Political Interest & $.273^{*}$ & .275 & .005 & $.272 *$ & .274 & .006 \\
\hline Risk Preference & $.095^{*}$ & .079 & .005 & $.110^{*}$ & .092 & .006 \\
\hline Risk Preference $\mathrm{x}$ Interest & $.047 *$ & .038 & .004 & $.067 *$ & .053 & .005 \\
\hline$R^{2}$ & & 23 & & & 26 & \\
\hline$N$ & & 574 & & & 574 & \\
\hline
\end{tabular}

Notes: $* p<.05$ for covariates and $p<$ FDR adjusted $q$ for the main and interactive effect of risk preference (estimates available in the supplemental file). Stand.

$=$ Standardized. Est $=$ Estimate. $\mathrm{SE}=$ Standard Error. Age coded $0=$ under $18,1=$ over 18 . 
Table 5

Standardized Estimates, Unstandardized Estimates, and Standard Errors for Regression Models Predicting Social Movement Intent among Youth who have not yet Participated

\begin{tabular}{lcccccc}
\hline & \multicolumn{3}{c}{ Boy cott } & \multicolumn{3}{c}{ Protest } \\
\cline { 2 - 7 } & Stand. Est. & Est. & SE & Stand. Est. & Est. & SE \\
\hline Age & $.030^{*}$ & .080 & .012 & $.033^{*}$ & .086 & .012 \\
Female & $-.040^{*}$ & -.081 & .009 & $-.038^{*}$ & -.077 & .009 \\
Black & $-.042^{*}$ & -.116 & .014 & $-.056^{*}$ & -.156 & .015 \\
Hispanic & $-.015^{*}$ & -.076 & .027 & $-.019^{*}$ & -.099 & .027 \\
Parents' Education & $.091^{*}$ & .076 & .004 & $.084^{*}$ & .070 & .004 \\
Political Ideology & $.110^{*}$ & .116 & .005 & $.156^{*}$ & .163 & .005 \\
Cohort & $-.048^{*}$ & -.043 & .004 & $-.040^{*}$ & -.039 & .004 \\
Election Year & $.021^{*}$ & .048 & .010 & .005 & .012 & .010 \\
& & & & & & \\
Clubs & $.058^{*}$ & .050 & .005 & $.073^{*}$ & .063 & .005 \\
Arts & $.079^{*}$ & .052 & .004 & $.102^{*}$ & .067 & .004 \\
Athletic & -.006 & -.004 & .004 & $.016^{*}$ & .009 & .004 \\
Other & $.098^{*}$ & .064 & .004 & $.155^{*}$ & .101 & .004 \\
Community Service & $.074^{*}$ & .074 & .004 & $.132^{*}$ & .132 & .004 \\
Religious Involvement & .009 & .008 & .004 & -.005 & -.004 & .004 \\
Victimization & $.091^{*}$ & .180 & .009 & $.113^{*}$ & .224 & .008 \\
Delinquency & $.0777^{*}$ & .191 & .011 & $.076^{*}$ & .188 & .011 \\
Substance Use & $.055^{*}$ & .030 & .002 & $.068^{*}$ & .037 & .002 \\
Political Interest & & & & & & \\
Risk Preference & $.223^{*}$ & .229 & .004 & $.312^{*}$ & .318 & .004 \\
Risk Preference x Interest & $.058^{*}$ & .049 & .004 & $.094^{*}$ & .078 & .004 \\
$R^{2}$ & $.015^{*}$ & .012 & .004 & $.037^{*}$ & .030 & .004 \\
$N$ & & .12 & & & .23 & \\
\hline & & 100099 & & & 104058 & \\
\hline
\end{tabular}

Notes: ${ }^{*} p<.05$ for covariates and $p<$ FDR adjusted $q$ for the main and interactive effect of risk preference (estimates available in the supplemental file). Stand. $=$ Standardized. Est $=$ Estimate. $\mathrm{SE}=$ Standard Error. Age coded $0=$ under $18,1=$ over 18. 


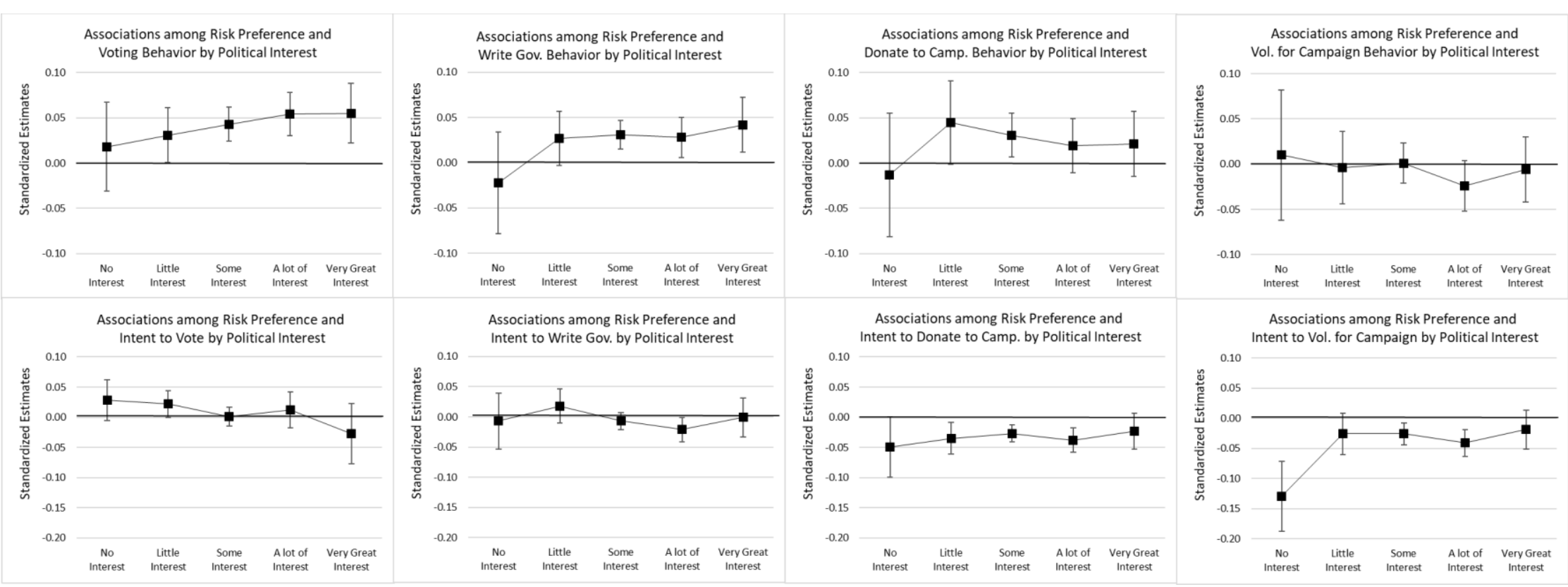

Figure 1. Associations among Risk Preference and Standard Political Behaviors and Intent by Political Interest. 


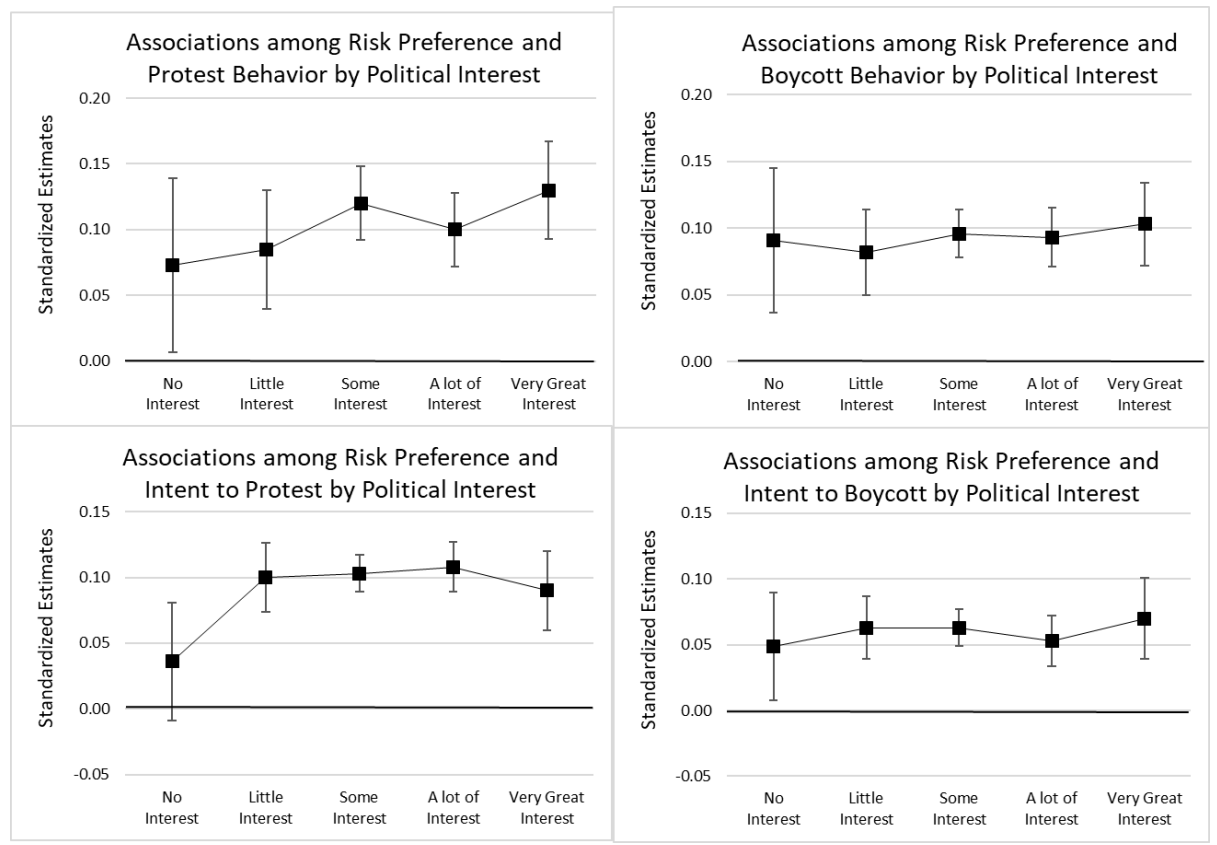

Figure 2. Associations among Risk Preference and Social Movement Behaviors and Intent by Political Interest. 


\section{Supplemental Material}

Table 1. Bivariate Correlations among Covariates and Political Intent.

Table 2. Wald Statistics Comparing the Effect of Risk Preference on Social Movement and Standard Political Behavior and Intent.

Table 3. False Discovery Rate Calculations.

Table 4. Standardized Estimates, Unstandardized Estimates, and Standard Errors for Multinomial Probit Regression Models Predicting Intent and Non-Intent/Behavior Relative to Past Standard Political Behavior

Table 5. Standardized Estimates, Unstandardized Estimates, and Standard Errors for Multinomial Probit Regression Models Predicting Intent and Non-Intent/Behavior Relative to Past Standard Political Behavior

Table 6. Standardized Estimates, Unstandardized Estimates, and Standard Errors for Multinomial Probit Regression Models Predicting Intent and Non-Intent/Behavior Relative to Past Social Movement Behavior 
Table 1

Bivariate Correlations among Covariates and Political Intent

\begin{tabular}{lcccccc}
\hline & $\begin{array}{c}\text { Vote } \\
\text { Intent }\end{array}$ & $\begin{array}{c}\text { Volunteer Camp. } \\
\text { Intent }\end{array}$ & $\begin{array}{c}\text { Donate Camp. } \\
\text { Intent }\end{array}$ & $\begin{array}{c}\text { Write Gov. } \\
\text { Intent }\end{array}$ & $\begin{array}{c}\text { Boycott } \\
\text { Intent }\end{array}$ & $\begin{array}{c}\text { Protest } \\
\text { Intent }\end{array}$ \\
\hline 1. Age (18+) & $.01^{*}$ & $.03^{*}$ & $.03^{*}$ & $.07^{*}$ & $.02^{*}$ & $.02^{*}$ \\
2. Gender & -.05 & $.03^{*}$ & $.02^{*}$ & $-.04^{*}$ & $-.03^{*}$ & $-.03^{*}$ \\
3. Black & $-.12^{*}$ & $.02^{*}$ & $-.02^{*}$ & .00 & $.01^{*}$ & $.02^{*}$ \\
4. Hispanic & $-.12^{*}$ & $.02^{*}$ & $-.02^{*}$ & .00 & $.01^{*}$ & $.02^{*}$ \\
5. Parents Edu & $.15^{*}$ & $.04^{*}$ & $.07^{*}$ & $.07^{*}$ & $.06^{*}$ & $.06^{*}$ \\
6. Political Ideology & $.11^{*}$ & $.04^{*}$ & $.05^{*}$ & $.07^{*}$ & $.07^{*}$ & $.09^{*}$ \\
7. Cohort & $-.06^{*}$ & $-.05^{*}$ & $-.06^{*}$ & $-.12^{*}$ & $-.03^{*}$ & $-.03^{*}$ \\
8. Election Year & $.02^{*}$ & $.02^{*}$ & $.02^{*}$ & $.01^{*}$ & $.02^{*}$ & .00 \\
9. Clubs & $.05^{*}$ & $.08^{*}$ & $.05^{*}$ & $.07^{*}$ & $.04^{*}$ & $.05^{*}$ \\
10. Arts & $.08^{*}$ & $.06^{*}$ & $.05^{*}$ & $.08^{*}$ & $.06^{*}$ & $.07^{*}$ \\
11. Athletic & $.10^{*}$ & $.02^{*}$ & $.04^{*}$ & $.03^{*}$ & .00 & $.01^{*}$ \\
12. Other & $.16^{*}$ & $.12^{*}$ & $.11^{*}$ & $.13^{*}$ & $.07^{*}$ & $.11^{*}$ \\
13. Com Service & $.10^{*}$ & $.11^{*}$ & $.09^{*}$ & $.13^{*}$ & $.05^{*}$ & $.09^{*}$ \\
14. Religious Ser Att. & $.10^{*}$ & $.05^{*}$ & $.06^{*}$ & $.06^{*}$ & $.01^{*}$ & .00 \\
15. Victimization & $-.04^{*}$ & $.03^{*}$ & $.01^{*}$ & $.05^{*}$ & $.07^{*}$ & $.08^{*}$ \\
16. Delinquency & $-.03^{*}$ & .00 & $-.01^{*}$ & $.00^{*}$ & $.03^{*}$ & $.03^{*}$ \\
17. Substance Use & $.06^{*}$ & $-.03^{*}$ & .00 & $.01^{*}$ & $.03^{*}$ & $.04^{*}$ \\
18. Political Interest & $.27^{*}$ & $.21^{*}$ & $.19^{*}$ & $.28^{*}$ & $.16^{*}$ & $.22^{*}$ \\
19. Risk Taking & .00 & $-.02^{*}$ & $-.02^{*}$ & .00 & $.04^{*}$ & $.06^{*}$ \\
\hline
\end{tabular}

Notes: $* p<.05 . \mathrm{SP}=$ Standard Political. $\mathrm{SM}=$ Social Movement. 
Table 2

Wald Statistics Comparing the Effect of Risk Preference on Social Movement and Standard Political Behavior and Intent.

\begin{tabular}{lcccc}
\hline & Voting & Donating to a Campaign & Working for a Campaign & Writing Government \\
\hline Boycotting Behavior & 32.00 & 49.59 & 110.23 & 68.51 \\
Protesting Behavior & 46.05 & 64.22 & 125.35 & 83.77 \\
Boycotting Intent & 1653.13 & 1984.50 & 1524.39 & 1696.53 \\
Protesting Intent & 3180.03 & 3633.78 & 2802.95 & 3240.13 \\
\hline
\end{tabular}

Notes: All values were estimated with 1 degree of freedom and were significant at $\mathrm{p}<.001$. 
Table 3

False Discover Rate Calculations

\begin{tabular}{lcccc}
\hline & \multicolumn{2}{c}{$\begin{array}{c}\text { Main Effect of Risk } \\
\text { Preference }\end{array}$} & $\begin{array}{c}\text { Risk Preference x Political Interest } \\
\text { Interaction }\end{array}$ \\
\cline { 2 - 5 } Model & $p$ value & FDR Adjusted $\mathrm{q}$ & $p$ value & FDR Adjusted q \\
\hline Behavior & $<.001$ & .0063 & $<.001$ & .0167 \\
$\quad$ Vote & $<.001$ & .0146 & .004 & .0333 \\
Donate to Campaign & .615 & .0458 & .786 & .0479 \\
Work for Campaign & $<.001$ & .0042 & $<.001$ & .0125 \\
Write Government & $<.001$ & .0292 & $<.001$ & .0104 \\
Boycott & $<.001$ & .0271 & $<.001$ & .0083 \\
Demonstrate & & & & .0354 \\
Intent & .803 & .0500 & .008 & .0396 \\
Vote & $<.001$ & .0250 & .204 & .0375 \\
Donate to Campaign & $<.001$ & .0229 & .035 & .0417 \\
Work for Campaign & .271 & .0438 & .221 & .0313 \\
Write Government & $<.001$ & .0208 & .001 & .0021 \\
Boycott & $<.001$ & .0188 & $<.001$ & \\
Demonstrate & & & & \\
\hline
\end{tabular}


Table 4

Standardized Estimates, Unstandardized Estimates, and Standard Errors for Multinomial Probit Regression Models Predicting Intent and Non-Intent/Behavior Relative to Past Standard Political Behavior

\begin{tabular}{|c|c|c|c|c|c|c|c|c|c|c|c|c|}
\hline & \multicolumn{6}{|c|}{ Vote } & \multicolumn{6}{|c|}{ Donate to Campaign } \\
\hline & \multicolumn{3}{|c|}{ Intent } & \multicolumn{3}{|c|}{ No Intent/Behavior } & \multicolumn{3}{|c|}{ Intent } & \multicolumn{3}{|c|}{ No Intent/Behavior } \\
\hline & $\bar{\beta}$ & $\overline{\mathrm{B}}$ & $S E$ & $\beta$ & $\bar{B}$ & $S E$ & $\bar{\beta}$ & $\overline{\mathrm{B}}$ & $S E$ & $\beta$ & $\bar{B}$ & $S E$ \\
\hline Age & $-.30^{*}$ & -.79 & .02 & $-.35^{*}$ & -1.02 & .03 & $-.03^{*}$ & -.09 & .03 & $-.06^{*}$ & -.17 & .02 \\
\hline Female & $.13^{*}$ & .26 & .01 & $.14^{*}$ & .28 & .02 & $.05^{*}$ & .10 & .02 & $.02 *$ & .04 & .02 \\
\hline Black & $-.09 *$ & -.26 & .02 & $-.10^{*}$ & -.25 & .02 & .01 & .03 & .03 & $.03 *$ & .08 & .02 \\
\hline Hispanic & $.04 *$ & .23 & .04 & $.17 *$ & .77 & .06 & $.03 *$ & .18 & .07 & $.05 *$ & .26 & .05 \\
\hline Parents' Education & $-.07 *$ & -.06 & .01 & $-.34 *$ & -.27 & .01 & .01 & .01 & .01 & $-.07 *$ & -.06 & .01 \\
\hline Political Ideology & $.07 *$ & .07 & .01 & $.06 *$ & .06 & .01 & $-.05^{*}$ & -.05 & .01 & $-.02 *$ & -.02 & .01 \\
\hline Cohort & $-.10^{*}$ & -.09 & .01 & $-.02 *$ & -.02 & .01 & $.05 *$ & .05 & .01 & $.11^{*}$ & .10 & .01 \\
\hline Election Year & $-.13^{*}$ & -.28 & .01 & $-.19 *$ & -.42 & .02 & .01 & .03 & .02 & -.01 & -.03 & .02 \\
\hline Clubs & $-.02 *$ & -.02 & .01 & $-.12 *$ & -.11 & .01 & $-.07 *$ & -.06 & .01 & $-.11 *$ & -.09 & .01 \\
\hline Arts & $-.03^{*}$ & -.02 & .01 & $-.17^{*}$ & -.12 & .01 & $-.07 *$ & -.04 & .01 & $-.10^{*}$ & -.07 & .01 \\
\hline Athletic & $-.06^{*}$ & -.03 & .00 & $-.25^{*}$ & -.15 & .01 & $.05^{*}$ & .03 & .01 & -.02 & -.01 & .01 \\
\hline Other & $-.03 *$ & -.02 & .01 & $-.30^{*}$ & -.19 & .01 & $-.04 *$ & -.03 & .01 & $-.16^{*}$ & -.10 & .01 \\
\hline Community Service & $-.07 *$ & -.07 & .01 & $-.24 *$ & -.22 & .01 & $-.08^{*}$ & -.08 & .01 & $-.16^{*}$ & -.16 & .01 \\
\hline Religious Involvement & $-.01 *$ & -.01 & .01 & $-.18^{*}$ & -.15 & .01 & $.06^{*}$ & .06 & .01 & $-.02 *$ & -.02 & .01 \\
\hline Victimization & $-.07 *$ & -.13 & .01 & $-.02 *$ & -.04 & .02 & $-.14 *$ & -.26 & .02 & $-.11 *$ & -.22 & .01 \\
\hline Delinquency & $-.06^{*}$ & -.14 & .01 & $.07 *$ & .12 & .02 & $-.13^{*}$ & -.29 & .02 & $-.08^{*}$ & -.18 & .02 \\
\hline Substance Use & .00 & .00 & .00 & $-.04 *$ & -.02 & .01 & $-.09 *$ & -.05 & .01 & $-.07 *$ & -.04 & .00 \\
\hline Political Interest & $-.12 *$ & -.13 & .01 & $-.52 *$ & -.46 & .01 & $-.08 *$ & -.08 & .01 & $-.28 *$ & -.29 & .01 \\
\hline Risk Preference & $-.05^{*}$ & -.04 & .01 & $-.06^{*}$ & -.05 & .01 & $-.06^{*}$ & -.05 & .01 & $-.03^{*}$ & -.02 & .01 \\
\hline Risk Preference $\mathrm{x}$ Interest & $-.03 *$ & -.02 & .00 & $-.04 *$ & -.03 & .01 & -.02 & -.01 & .01 & $-.02 *$ & -.02 & .01 \\
\hline$R^{2}$ & & & & 18 & & & & & & & & \\
\hline$N$ & & & & 9574 & & & & & & & & \\
\hline
\end{tabular}

Notes: $* p<.05$ for covariates and $p<$ FDR adjusted $q$ for the main and interactive effect of risk preference (estimates available in the supplemental file). Stand.

$=$ Standardized. Est $=$ Estimate. $\mathrm{SE}=$ Standard Error. Age coded $0=$ under $18,1=$ over 18 . 
Table 5

Standardized Estimates, Unstandardized Estimates, and Standard Errors for Multinomial Probit Regression Models Predicting Intent and Non-Intent/Behavior Relative to Past Standard Political Behavior

\begin{tabular}{|c|c|c|c|c|c|c|c|c|c|c|c|c|}
\hline & \multicolumn{6}{|c|}{ Work for a Campaign } & \multicolumn{6}{|c|}{ Write Government } \\
\hline & \multicolumn{3}{|c|}{ Intent } & \multicolumn{3}{|c|}{ No Intent/Behavior } & \multicolumn{3}{|c|}{ Intent } & \multicolumn{3}{|c|}{ No Intent/Behavior } \\
\hline & $\beta$ & $\mathrm{B}$ & $S E$ & $\beta$ & B & $S E$ & $\beta$ & $\mathrm{B}$ & $S E$ & $\beta$ & $\mathrm{B}$ & $S E$ \\
\hline Age & $-.04 *$ & -.11 & .03 & $-.08 *$ & -.20 & .02 & $.07 *$ & .07 & .01 & $-.03^{*}$ & -.08 & .01 \\
\hline Female & $.05^{*}$ & .11 & .02 & .00 & .00 & .01 & $-.03 *$ & -.03 & .01 & $.03 *$ & .06 & .01 \\
\hline Black & .02 & .06 & .04 & $.08 *$ & .22 & .02 & $-.11^{*}$ & -.11 & .01 & $.03^{*}$ & .08 & .02 \\
\hline Hispanic & $.06^{*}$ & .38 & .09 & $.07 *$ & .35 & .05 & $.04 *$ & .04 & .01 & $.09 *$ & .47 & .04 \\
\hline Parents' Education & $-.10^{*}$ & -.08 & .01 & $-.14 *$ & -.12 & .01 & $-.09 *$ & -.09 & .01 & $-.17 *$ & -.14 & .00 \\
\hline Political Ideology & .00 & .00 & .01 & -.01 & -.01 & .01 & $-.03 *$ & -.03 & .01 & $-.03 *$ & -.03 & .01 \\
\hline Cohort & $.10^{*}$ & .09 & .01 & $.16^{*}$ & .14 & .01 & $-.09 *$ & -.09 & .01 & $.08^{*}$ & .07 & .01 \\
\hline Election Year & -.01 & -.01 & .02 & $-.04 *$ & -.08 & .02 & .01 & .01 & .01 & -.01 & -.02 & .01 \\
\hline Clubs & .00 & .00 & .01 & $-.11 *$ & -.09 & .01 & $-.02 *$ & -.02 & .01 & $-.11 *$ & -.09 & .01 \\
\hline Arts & -.01 & -.01 & .01 & $-.10^{*}$ & -.06 & .01 & $-.06 *$ & -.06 & .01 & $-.15^{*}$ & -.10 & .00 \\
\hline Athletic & $-.04 *$ & -.02 & .01 & $-.06^{*}$ & -.04 & .01 & $-.03 *$ & -.03 & .01 & $-.06^{*}$ & -.04 & .00 \\
\hline Other & -.01 & -.01 & .01 & $-.21 *$ & -.14 & .01 & $-.07 *$ & -.07 & .01 & $-.23^{*}$ & -.15 & .00 \\
\hline Com & $-.04 *$ & -.03 & .01 & $-.18^{*}$ & -.18 & .01 & $-.09 *$ & -.09 & .01 & $-.23 *$ & -.23 & .01 \\
\hline is Involv & -.02 & -.02 & .01 & $-.09 *$ & -.08 & .01 & $-.02 *$ & -.02 & .01 & $-.09 *$ & -.08 & .01 \\
\hline Victimization & $-.05^{*}$ & -.09 & .02 & $-.08^{*}$ & -.15 & .01 & $-.03 *$ & -.03 & .01 & $-.09 *$ & -.18 & .01 \\
\hline Delinquency & $-.06 *$ & -.13 & .02 & $-.05^{*}$ & -.12 & .01 & $-.02 *$ & -.02 & .01 & $-.02 *$ & -.04 & .01 \\
\hline Subs & $-.12 *$ & -.07 & .01 & $-.06^{*}$ & -.03 & .00 & $-.03 *$ & -.03 & .01 & $-.03 *$ & -.02 & .00 \\
\hline Political Interest & $.05^{*}$ & .05 & .01 & $-.28 *$ & -.29 & .01 & -.01 & -.01 & .01 & $-.37 *$ & -.38 & .00 \\
\hline Risk Preference & $-.02 *$ & -.02 & .01 & .01 & .01 & .01 & $-.04 *$ & -.04 & .01 & $-.03 *$ & -.03 & .01 \\
\hline Risk Preference $\mathrm{x}$ Interest & .01 & .01 & .01 & .00 & .00 & .01 & $-.03^{*}$ & -.03 & .01 & $-.03^{*}$ & -.03 & .00 \\
\hline$R^{2}$ & \multicolumn{6}{|c|}{.19} & \multicolumn{6}{|c|}{.22} \\
\hline$N$ & \multicolumn{6}{|c|}{109574} & \multicolumn{6}{|c|}{109574} \\
\hline
\end{tabular}

Notes: ${ }^{*} p<.05$ for covariates and $p<$ FDR adjusted $q$ for the main and interactive effect of risk preference (estimates available in the supplemental file). Stand. $=$ Standardized. Est $=$ Estimate. $\mathrm{SE}=$ Standard Error. Age coded $0=$ under $18,1=$ over 18. 
Table 6

Standardized Estimates, Unstandardized Estimates, and Standard Errors for Multinomial Probit Regression Models Predicting Intent and Non-Intent/Behavior Relative to Past Social Movement Behavior

\begin{tabular}{|c|c|c|c|c|c|c|c|c|c|c|c|c|}
\hline & \multicolumn{6}{|c|}{ Boycott } & \multicolumn{6}{|c|}{ Protest } \\
\hline & \multicolumn{3}{|c|}{ Intent } & \multicolumn{3}{|c|}{ No Intent/Behavior } & \multicolumn{3}{|c|}{ Intent } & \multicolumn{3}{|c|}{ No Intent/Behavior } \\
\hline & $\beta$ & $\mathrm{B}$ & $S E$ & $\beta$ & $\mathrm{B}$ & $S E$ & $\beta$ & $\mathrm{B}$ & $S E$ & $\beta$ & $\mathrm{B}$ & $S E$ \\
\hline Age & $.06^{*}$ & .15 & .02 & $.02 *$ & .06 & .02 & $.04 *$ & .10 & .03 & .01 & .01 & .02 \\
\hline Female & $-.02 *$ & -.04 & .02 & $.02 *$ & .04 & .01 & $.03^{*}$ & .06 & .02 & $.05^{*}$ & .11 & .02 \\
\hline Black & $-.08^{*}$ & -.23 & .02 & $-.03 *$ & -.09 & .02 & $-.06^{*}$ & -.19 & .03 & -.01 & -.02 & .02 \\
\hline Hispanic & $.05^{*}$ & .27 & .05 & $.06^{*}$ & .29 & .04 & .02 & .13 & .07 & $.03 *$ & .18 & .05 \\
\hline Parents' Education & $-.13^{*}$ & -.11 & .01 & $-.19 *$ & -.16 & .01 & $-.13^{*}$ & -.10 & .01 & $-.17 *$ & -.14 & .01 \\
\hline Political Ideology & $-.06^{*}$ & -.05 & .01 & $-.14 *$ & -.15 & .01 & $-.04 *$ & -.03 & .01 & $-.16^{*}$ & -.17 & .01 \\
\hline Cohort & $-.09 *$ & -.08 & .01 & $-.03 *$ & -.03 & .01 & $-.05^{*}$ & -.05 & .01 & -.01 & -.01 & .01 \\
\hline Election Year & $.02 *$ & .05 & .02 & .00 & .00 & .01 & .01 & .01 & .02 & .00 & .00 & .02 \\
\hline Clubs & $-.06^{*}$ & -.05 & .01 & $-.10 *$ & -.09 & .01 & $-.07 *$ & -.05 & .01 & $-.11 *$ & -.09 & .01 \\
\hline Arts & $-.09 *$ & -.06 & .01 & $-.14 *$ & -.09 & .01 & $-.11 *$ & -.07 & .01 & $-.16^{*}$ & -.11 & .01 \\
\hline Athletic & $.03 *$ & .02 & .01 & $.03 *$ & .02 & .00 & .01 & .01 & .01 & .00 & .00 & .01 \\
\hline Other & $-.08^{*}$ & -.06 & .01 & $-.16^{*}$ & -.10 & .01 & $-.06^{*}$ & -.04 & .01 & $-.17 *$ & -.11 & .01 \\
\hline Community Service & $-.13^{*}$ & -.12 & .01 & $-.17 *$ & -.17 & .01 & $-.12 *$ & -.11 & .01 & $-.19 *$ & -.19 & .01 \\
\hline Religious Involvement & .01 & .00 & .01 & .00 & .00 & .01 & .01 & .01 & .01 & .01 & .01 & .01 \\
\hline Victimization & $-.10^{*}$ & -.17 & .01 & $-.15^{*}$ & -.30 & .01 & $-.11 *$ & -.19 & .02 & $-.16^{*}$ & -.32 & .01 \\
\hline Delinquency & $-.06^{*}$ & -.14 & .02 & $-.11 *$ & -.27 & .01 & $-.10^{*}$ & -.22 & .02 & $-.13 *$ & -.31 & .01 \\
\hline Substance Use & $-.04 *$ & -.02 & .00 & $-.08 *$ & -.05 & .00 & $-.08 *$ & -.04 & .01 & $-.12 *$ & -.07 & .00 \\
\hline Political Interest & $-.15^{*}$ & -.15 & .01 & $-.32 *$ & -.32 & .01 & $-.10^{*}$ & -.10 & .01 & $-.32 *$ & -.33 & .01 \\
\hline Risk Preference & $-.07 *$ & -.06 & .01 & $-.11 *$ & -.09 & .01 & $-.06^{*}$ & -.05 & .01 & $-.13 *$ & -.11 & .01 \\
\hline Risk Preference $\mathrm{x}$ Interest & $-.04 *$ & -.03 & .01 & $-.05^{*}$ & -.04 & .00 & $-.05^{*}$ & -.04 & .01 & $-.07 *$ & -.06 & .01 \\
\hline$R^{2}$ & \multicolumn{6}{|c|}{.23} & \multicolumn{6}{|c|}{.26} \\
\hline$N$ & \multicolumn{6}{|c|}{109574} & \multicolumn{6}{|c|}{109574} \\
\hline
\end{tabular}

Notes: $* p<.05$ for covariates and $p<$ FDR adjusted $q$ for the main and interactive effect of risk preference (estimates available in the supplemental file). Stand.

$=$ Standardized. Est $=$ Estimate. SE $=$ Standard Error. Age coded $0=$ under $18,1=$ over 18 . 